\title{
Deciphering Spinal Endogenous Dopaminergic Mechanisms That Modulate Micturition Reflexes in Rats with Spinal Cord Injury
}

\author{
Shaoping Hou, ${ }^{1}$ Jaclyn H. DeFinis, ${ }^{1}$ Stephanie L. Daugherty, ${ }^{2}$ Chuanxi Tang, ${ }^{1}$ Jeremy Weinberger, ${ }^{1}$ and \\ William C. de Groat ${ }^{2}$
}

https://doi.org/10.1523/ENEURO.0157-21.2021

${ }^{1}$ Marion Murray Spinal Cord Research Center, Department of Neurobiology and Anatomy, Drexel University College of Medicine, Philadelphia, PA 19129 and ${ }^{2}$ Department of Pharmacology and Chemical Biology, University of Pittsburgh School of Medicine, Pittsburgh, PA 15261

\section{Visual Abstract}

Spinal Dopamine Neurons
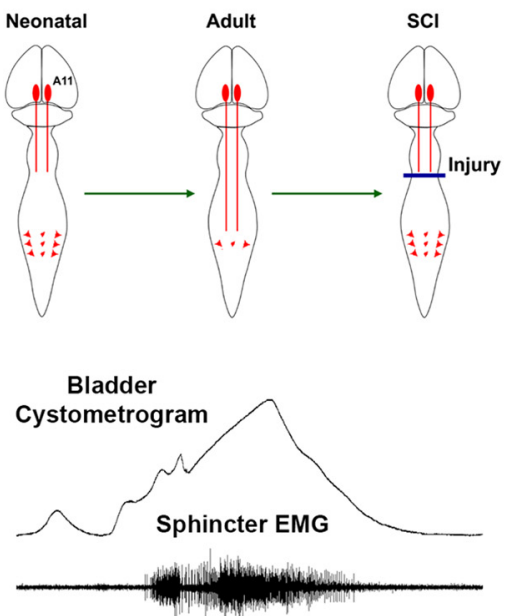

Dopamine Receptors for EUS Activity

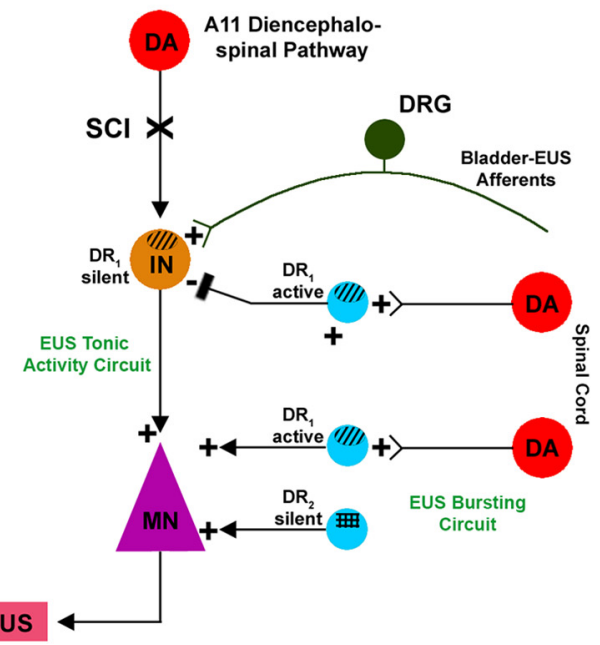

Spinal neuronal mechanisms regulate recovered involuntary micturition after spinal cord injury (SCl). It was recently discovered that dopamine (DA) is synthesized in the rat injured spinal cord and is involved in lower urinary tract (LUT) activity. To fully understand the role of spinal DAergic machinery in micturition, we examined

\section{Significance Statement}

We employed pharmacological interventions of spinal endogenous dopaminergic (DAergic) pathways to decode the machinery of bladder and sphincter reflexes in female rats with spinal cord injury (SCl). Consequently, tonically active $\mathrm{D}_{1}$-like receptors $\left(\mathrm{DR}_{1}\right)$ in $\mathrm{SCl}$ rats inhibit urine storage and enhance voiding by differentially modulating external urethral sphincter (EUS) tonic and bursting patterns, respectively, while pharmacologic activation of $\mathrm{DR}_{2}$, which are normally silent, improves voiding by increasing EUS bursting. Enhancing DA signaling with L-DOPA or apomorphine (APO) achieves better detrusor-sphincter coordination to facilitate micturition function in SCI rats. Therefore, spinal DAergic mechanisms play an important role in recovered micturition function and may serve as a novel therapeutic target after SCl. 
urodynamic responses in female rats during pharmacological modulation of the DA pathway. Three to four weeks after complete thoracic SCI, the DA precursor L-DOPA administered intravenously during bladder cystometrogram (CMG) and external urethral sphincter (EUS) electromyography (EMG) reduced bladder overactivity and increased the duration of EUS bursting, leading to remarkably improved voiding efficiency. Apomorphine (APO), a non-selective DA receptor (DR) agonist, or quinpirole, a selective $\mathrm{DR}_{2}$ agonist, induced similar responses, whereas a specific $\mathrm{DR}_{2}$ antagonist remoxipride alone had only minimal effects. Meanwhile, administration of SCH 23390, a $\mathrm{DR}_{1}$ antagonist, reduced voiding efficiency by increasing tonic EUS activity and shortening the EUS bursting period. Unexpectedly, SKF 38393, a selective $\mathrm{DR}_{1}$ agonist, increased EUS tonic activity, implying a complicated role of $\mathrm{DR}_{1}$ in LUT function. In metabolic cage assays, subcutaneous administration of quinpirole decreased spontaneous voiding frequency and increased voiding volume; L-DOPA and APO were inactive possibly because of slow entry into the CNS. Collectively, tonically active $\mathrm{DR}_{1}$ in $\mathrm{SCl}$ rats inhibit urine storage and enhance voiding by differentially modulating EUS tonic and bursting patterns, respectively, while pharmacologic activation of $\mathrm{DR}_{2}$, which are normally silent, improves voiding by enhancing EUS bursting. Thus, enhancing DA signaling achieves better detrusor-sphincter coordination to facilitate micturition function in $\mathrm{SCl}$ rats.

Key words: bladder overactivity; bursting; detrusor-sphincter dyssynergia; dopamine receptor; tonic activity

\section{Introduction}

Traumatic spinal cord injury (SCl) often interrupts the spinobulbospinal micturition reflex pathway and immediately produces an areflexic bladder. Over time, lower urinary function spontaneously recovers because of the emergence of a spinal micturition reflex, which takes approximately two to three weeks in rats or a few months in humans (de Groat, 1995; Fowler et al., 2008). However, the occurrence of bladder hyperactivity and detrusorsphincter dyssynergia (DSD) causes incontinence and inefficient emptying, resulting in recurrent lower urinary tract (LUT) infections. Furthermore, persistent urinary retention and high intravesical pressure give rise to vesicoureteral reflux that may lead to upper urinary tract deterioration and even renal failure (Zinck and Downie, 2006). Currently, there is no effective drug to treat these disorders in SCl patients.

Multiple neurotransmitters are related to the control of micturition function. Patients with Parkinson's disease who have an impaired dopamine (DA) system in the midbrain often experience irritable hyperactive bladder symptoms (Winge and Fowler, 2006), suggesting a role of DA in the modulation of LUT activity by an action at the level of the pontine micturition center (Ogawa et al., 2006) or in the spinal cord. In the mammalian spinal cord, DA is

Received April 12, 2021; accepted June 30, 2021; First published July 8, 2021. The authors declare no competing financial interests.

Author contributions: S.H. and W.C.d.G. designed research; S.H., J.H.D., S.L.D., C.T., and J.W. performed research; S.H., J.H.D., S.L.D., C.T., and J.W. analyzed data; S.H., W.C.d.G., and J.H.D. wrote the paper.

This work was supported by National Institutes of Health National Institute of Neurological Disorders and Stroke Grant R01NS099076 (to S.H.) and National Institute of Diabetes and Digestive and Kidney Diseases Grants F31DK123840-01 (to J.H.D.) and PO1DK093424 (to W.C.d.G.).

Correspondence should be addressed to Shaoping Hou at sh698@ drexel.edu.

https://doi.org/10.1523/ENEURO.0157-21.2021

Copyright (C) 2021 Hou et al.

This is an open-access article distributed under the terms of the Creative Commons Attribution 4.0 International license, which permits unrestricted use, distribution and reproduction in any medium provided that the original work is properly attributed. expressed in diencephalospinal pathways originating in the A11 cell group (Skagerberg and Lindvall, 1985). Although there is no systemic study to show the relation between these descending projections and LUT function, sporadic pieces of evidence support this possibility (Ozawa et al., 2017; Koblinger et al., 2018). Previous studies revealed strong expression of various DA receptors (DRs) in autonomic regions of the mammalian spinal cord as well as in sexually dimorphic spinal motor nuclei (van Dijken et al., 1996). Apomorphine (APO), a non-selective DR agonist, was demonstrated to enable an erection in SCl rats (Ishizuka et al., 2002) and increase bladder activity in SCl patients (Steers et al., 2000). It was recently reported that a subpopulation of tyrosine hydroxylase $(\mathrm{TH})^{+}$ and/or DA decarboxylase (DDC) ${ }^{+}$cells residing in the rat caudal spinal cord may be the source of spinally-derived DA (Hou et al., 2016). These spinal interneurons undergo plasticity following $\mathrm{SCl}$ to produce a low level of DA that may influence spinal bladder reflex circuits. These findings raise the possibility that there are endogenous DAergic mechanisms in the spinal cord that regulate urogenital activity after $\mathrm{SCl}$.

During postnatal development, synaptic reorganization within the spinal cord contributes to the maturation of neural regulation of lower urinary function. In this process, spinal micturition reflex mechanisms are gradually downregulated and replaced by supraspinal reflexes (Maggi et al., 1986; Araki and de Groat, 1997; de Groat, 2002). This can explain the elimination of spinally-mediated involuntary urination in neonates and the establishment of supraspinal control of urination in the adult. Likewise, the emergence of a spinal micturition reflex when $\mathrm{SCl}$ interrupts spinobulbospinal micturition reflex pathways is attributable to synaptic reorganization (de Groat et al., 1998) within distinct populations of interneurons involved in the spinal micturition reflex circuitry. Coincidently, it appears that the dynamic change in the source of DA in the spinal cord from diencephalospinal to intraspinal DAergic pathways maintains regulation of micturition function after SCl. This change may reflect a shift of DAergic modulation in different life stages or conditions ranging from neonate, adult, to the adult with $\mathrm{SCl}$ (Fig. 1). 


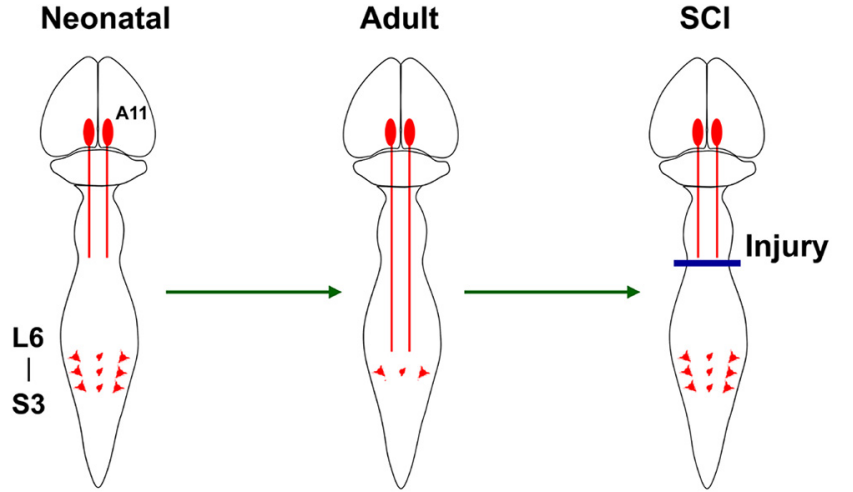

Figure 1. Hypothesis: spinal $\mathrm{TH}^{+}$neurons are unmasked as a primitive residual response to $\mathrm{SCl}$. During postnatal development, $\mathrm{TH}^{+}$neurons in the lumbosacral spinal cord contribute to DA synthesis and regulate pelvic organ function before diencephalospinal DAergic pathways originating from A11 cell groups develop. As the descending projections mature and dominate regulation of pelvic visceral activity, most spinal $\mathrm{TH}^{+}$neurons become silent because of competitive synapse formation. However, after SCl interrupts descending pathways, spinal $\mathrm{TH}^{+}$neurons undergo plasticity to augment DA synthesis and take over control of visceral activity to compensate for the loss of supraspinal DA control. Accordingly, we postulate that spinal endogenous DAergic mechanisms reemerge and regulate recovered micturition function following $\mathrm{SCl}$.

As preliminary findings revealed the involvement of spinal DAergic mechanisms in bladder control, it is particularly pivotal to elucidate how the coordination of detrusor and sphincter activity is regulated by the recovered spinal micturition reflex. Though previous studies showed that stimulating certain types of spinal DR increased the volume of urine expelled (Hou et al., 2016), they did not measure bladder capacity and postvoid residual bladder volume to determine whether improved voiding is caused by changes in urethral sphincter activity and increased voiding efficiency. Although administration of the DA precursor, L-DOPA, or the non-selective DR agonist, APO, can enhance voiding function in spinal intact subjects (Aranda and Cramer, 1993), it is unknown whether these strategies of enhancing DAergic mechanisms have similar effects on recovered micturition function after SCI. In the present study, we employed pharmacological interventions not only to answer these questions but to also test the possibility that manipulating this DAergic machinery can improve spontaneous urination in $\mathrm{SCl}$ rats.

\section{Materials and Methods}

\section{Animals}

A total of 89 adult female Wistar rats (weighing 200-250 g) were used. Institutional Animal Care and Use Committee and Society for Neuroscience guidelines on animal care were strictly followed to minimize potential suffering and the number of animals used.

\section{Spinal cord surgery}

Animals were anesthetized with $2 \%$ isoflurane. A partial laminectomy was performed at T8/9 vertebra to expose the dorsal spinal cord. To completely remove supraspinal control and the possibility of formation of descending propriospinal projections postinjury, animals underwent a complete spinal cord transection at the 10th thoracic (T10) level using a no. 11 blade. Lesion completeness was verified visually at the time of surgery. After active bleeding stopped, overlying musculature and skin were closed and lactated Ringer's solution ( $3 \mathrm{ml}$, Baxter Healthcare), cefazolin $(10 \mathrm{mg} / \mathrm{kg})$, and buprenex $(0.1 \mathrm{mg} /$ kg; Reckitt Benckiser) were subcutaneously administered. Bladders were manually expressed at least three times daily until killing.

\section{Bladder cystometrogram (CMG) and external urethral sphincter (EUS) electromyography (EMG) recordings}

Under extensive and careful bladder care, the spontaneous spinal micturition reflex is usually reestablished in approximately two to three weeks following SCl. Accordingly, bladder CMG and EUS EMG recordings were performed to assess the recovered bladder and sphincter reflexes three to four weeks after $\mathrm{SCl}$. All rats were anesthetized with isoflurane and placed in a supine position. A skin incision was made in the lower abdomen and muscles were separated to expose the urinary bladder. For bladder catheterization, the apex of the bladder dome was punctured using an 18-gauge needle. One collar-shaped end of a polyethylene catheter (PE-60; Clay Adams) was inserted into the bladder and sutured in place with a 6-0 silk thread (Mitsui et al., 2005a; Chang et al., 2007). Two Teflon-insulated platinum fine-wire electrodes (Astro-Med System, $50 \mu \mathrm{m}$ in diameter) were percutaneously inserted on both sides of the EUS via the vagina (Peng et al., 2006, 2008; Jiang et al., 2010). This was performed using a $30-G$ needle with the tip of the electrode hooked at the needle tip. The needle-guided electrode was inserted into the sphincter and then the needle was withdrawn to leave the wire embedded in the EUS muscle. As an alternative, two internal electrodes were also directly inserted into the EUS through the abdominal opening. The abdominal wall was then sutured closed with a 4-0 thread. To intravenously deliver pharmacological agents, a separate cannula (PE-10) filled with sterile saline was implanted in the right femoral vein. The peripheral end was connected to a $1 \mathrm{ml}$ syringe. In neuroaxis intact rats that were used to compare basal parameters of CMG and EMG reflexes with SCl rats $(n=6$ per group), urethane $(1.2 \mathrm{mg} / \mathrm{kg}$ ) was subcutaneously injected before the surgery and recordings were conducted under a lightly anesthetized state (Chang et al., 2007).

Immediately after removal of isoflurane, rats were placed in a restraining cage (KN-326, Natsume). The bladder catheter was connected to a pressure transducer and then to an amplifier (Transbridge, WPI) to record bladder pressure and to a microinjection syringe pump (4 M, WPI) for saline infusion by means of a four-way stopcock. For bladder CMG, room temperature saline was slowly infused into the bladder $(0.1 \mathrm{ml} / \mathrm{min})$ to mimic urine production by the kidney. To record EUS EMG activity, the inserted electrodes were connected to an alternating current amplifier (Model 1700; Astro-Med System) with low- 
cut and high-cut off at 300 and $500 \mathrm{~Hz}$ (Lee et al., 2013). CMG and EMG output were recorded and converted with a data acquisition starter kit (DI-1100, DataQ Instruments) on a computer system at a sampling rate of $1 \mathrm{kHz}$. After rats recovered from anesthesia within 10-15 min, we started infusing saline into the bladder but waited $\sim 1 \mathrm{~h}$ before starting pharmacological experiments to allow ample adaptation time. At least three to four continuous stable micturition cycles were collected predrug and postdrug delivery per rat. The urodynamic parameters measured included, the voiding amplitude (VA) defined as the difference between pressure at initiation of a bladder contraction and the peak intravesical pressure at the start of voiding (i.e., opening pressure), the voiding interval (VI) between two sequential voiding events, and the number of non-voiding contractions (NVCs) during the period of filling. NVCs were defined as rhythmic intravesical pressure increases $5 \mathrm{mmHg}$ from baseline without a release of fluid from the urethra (Mitsui et al., 2005b). Various EUS EMG parameters were also evaluated, such as EUS tonic activity in the filling phase before voiding and bursting period (BP) during voiding. Approximately $60-70 \%$ of untreated $\mathrm{SCl}$ rats exhibited sphincter bursting during voiding while the remainder exhibited increased amplitude tonic activity. The duration of the BP was therefore measured in three to four animals in each group. To quantify EUS tonic activity, the root mean square (RMS) and maximum amplitude of EMG activity were evaluated. The RMS represents the square root of the average power of the EMG signal for a given period of time to determine degree of activation (Falla et al., 2003). These two computercalculated parameters were examined during $5 \mathrm{~s}$ of a recording right before a void. Values were then calculated using the automatic function of the software. For each rat, the measurements in three to four voiding cycles before and after administration of vehicle or each drug were averaged to determine the mean value for statistical analysis. Animals were killed with an overdose of Euthasol at the end of the experiment.

\section{Evaluation of voiding efficiency during bladder CMG}

To accurately measure voiding efficiency, the bladder had to be completely emptied before infusing saline. Because emptying the bladder may interfere with the activity of the organ and sphincter in continuous CMG and EMG recordings, we thus used a different cohort of SCl rats whose bladder and right femoral vein were catheterized for CMG or drug delivery, respectively, but electrodes were not inserted into the EUS for EMG recordings (Kadekawa et al., 2016). Various parameters were measured including: (1) voiding volume, (2) residual volume, (3) bladder capacity (volume threshold), and (4) voiding efficiency. Animals were restrained as described above. After the voiding cycle was stable, the bladder was emptied by withdrawing the content through the catheter with a syringe. Then, saline was infused into the bladder $(0.1 \mathrm{ml} /$ min) until a void was induced. The pump was stopped immediately after voiding. The expelled saline and urine were manually collected into a small cup and the volume was measured. The residual volume in the bladder was withdrawn via the catheter and measured. Bladder capacity was calculated as the sum of voided and residual volumes; whereas voiding efficiency was calculated as the ratio of voided volume divided by bladder capacity. Drugs tested were L-DOPA (with carbidopa), carbidopa $(n=3)$, APO, remoxipride, quinpirole, SCH 23390, and SKF 38393 ( $n=4$ per drug except carbidopa). For each drug, the range of doses was the same as that in micturition reflex assessments. The order for reagent delivery was as follows: baseline, vehicle, drug from low to high concentrations, with intervals of at least $30 \mathrm{~min}$. After injecting vehicle or drug, the first void was not measured to eliminate potential artifacts from injection. The voiding and residual volumes in the ensuing three to four voids after each drug dose were measured and averaged for statistics.

\section{Pharmacological interventions}

Drugs were dissolved in $0.9 \%$ saline and administered intravenously after recording baseline urodynamic and EUS EMG activity and injection of $100 \mu$ of vehicle. The doses of the drugs used were chosen on the basis of previously published data (Yoshimura et al., 1998; Seki et al., 2001; Ogawa et al., 2006). All drugs were prepared in three concentrations to examine the effects of low, middle and high doses administered sequentially at an interval of at least $30 \mathrm{~min}$ (Table 1). The half-life information of each drug except SKF 38393 (Setler et al., 1978) was available in the literature: $1.5 \mathrm{~h}$ for L-DOPA (Calabrese et al., 2007; Contin and Martinelli, 2010), $1.8 \mathrm{~h}$ for carbidopa (Brooks, 2008), $33 \mathrm{~min}$ for APO (Gancher, 1995), $4.8 \mathrm{~h}$ for remoxipride (King et al., 1990; Movin-Osswald and HammarlundUdenaes, 1991), $9.5 \mathrm{~h}$ for quinpirole (Ballester González et al., 2015; Pértile et al., 2017), and $30 \mathrm{~min}$ for SCH 23390 (Hietala et al., 1992; Giorgi et al., 1993). When L-DOPA was tested, rats also received carbidopa (in a 1:10 ratio to the dose of L-DOPA) in the solution to inhibit peripheral effects of L-DOPA, as described below. Based on the observation that the bladder and sphincter retained proper responses for $>5-6 \mathrm{~h}$, the general protocol for drug testing was mainly conducted by administration of one drug in each rat, including $\mathrm{D}_{2}$-like receptor $\left(\mathrm{DR}_{2}\right)$ antagonist remoxipride $(n=6), \mathrm{DR}_{2}$ agonist quinpirole $(n=6), \mathrm{DR}_{1}$ antagonist $\mathrm{SCH}$ $23390(n=5), \mathrm{DR}_{1}$ agonist SKF $38393(n=5)$, and APO $(n=6)$, whereas in one group carbidopa was administered alone followed by L-DOPA with carbidopa $(n=6)$. To further verify effects mediated via specific receptors, a middle dose of the selective DR antagonists, including SCH 23390 or remoxipride, was administered after injection of L-DOPA or DR agonists to determine whether the antagonists could reverse the effects of the latter agents.

\section{Metabolic cage assays}

Three weeks after SCl, rats were placed into metabolic cages (Nalgene) to examine the spontaneous micturition pattern. The bladder was emptied by manual expression and before recording began, a 3-h equilibration period was allowed so that the rats could acclimate to the cage environment. Ample food pellets were provided. A total of $200 \mathrm{ml}$ of water was supplied in each cage and 
Table 1. Parameters of bladder CMGs and EUS EMG reflex assessments in SCI female rats

\begin{tabular}{|c|c|c|c|c|c|c|c|}
\hline \multirow[b]{3}{*}{ Drugs } & \multirow[b]{3}{*}{ Doses $(/ \mathrm{kg})$} & \multicolumn{3}{|c|}{ Bladder CMG } & \multicolumn{3}{|c|}{ EUS EMG } \\
\hline & & \multirow[b]{2}{*}{ VA } & \multirow[b]{2}{*}{ VI } & \multirow[b]{2}{*}{ NVCs } & \multicolumn{2}{|c|}{ Tonic } & \multirow[b]{2}{*}{ BP } \\
\hline & & & & & RMS & MA & \\
\hline (DA precursor) & $1.0 \mathrm{mg}$ & $0.89 \pm 0.05$ & $1.30 \pm 0.20$ & $0.86 \pm 0.21$ & $0.95 \pm 0.06$ & $0.98 \pm 0.03$ & $2.16 \pm 0.85$ \\
\hline \multirow[t]{2}{*}{$n=6$} & $10 \mathrm{mg}$ & $0.81 \pm 0.07$ & $1.64 \pm 0.47$ & $0.94 \pm 0.26$ & $0.82 \pm 0.06^{*}$ & $0.94 \pm 0.06^{*}$ & $3.39 \pm 1.59$ \\
\hline & $30 \mathrm{mg}$ & $0.73 \pm 0.03^{*}$ & $1.50 \pm 0.38$ & $0.81 \pm 0.13^{\star}$ & $0.74 \pm 0.08^{\star \star \star}$ & $0.83 \pm 0.03^{\star \#}$ & $4.75 \pm 2.21^{\star \star}$ \\
\hline$n=6$ & $10 \mu \mathrm{g}$ & $1.07 \pm 0.08$ & $1.22 \pm 0.14$ & $0.72 \pm 0.23$ & $0.69 \pm 0.08^{* \star}$ & $0.90 \pm 0.18$ & $1.40 \pm 0.11$ \\
\hline & $0.1 \mathrm{mg}$ & $0.98 \pm 0.02$ & $1.42 \pm 0.23$ & $0.45 \pm 0.18^{*}$ & $0.65 \pm 0.06^{*}$ & $0.61 \pm 0.05^{\star \star \#}$ & $2.20 \pm 0.44^{*}$ \\
\hline \multirow{4}{*}{$\begin{array}{l}\text { Remoxipride } \\
\qquad\left(\mathrm{DR}_{2} \text { antagonist) }\right. \\
n=6\end{array}$} & Saline & $0.96 \pm 0.13$ & $1.00 \pm 0.16$ & $1.00 \pm 0.34$ & $1.02 \pm 0.03$ & $0.98 \pm 0.04$ & $0.92 \pm 0.23$ \\
\hline & $0.1 \mathrm{mg}$ & $0.97 \pm 0.13$ & $1.04 \pm 0.13$ & $1.00 \pm 0.23$ & $0.98 \pm 0.02$ & $0.86 \pm 0.03$ & $0.98 \pm 0.17$ \\
\hline & $1.0 \mathrm{mg}$ & $0.93 \pm 0.08$ & $1.14 \pm 0.12$ & $1.50 \pm 0.14$ & $1.02 \pm 0.04$ & $1.23 \pm 0.28$ & $0.67 \pm 0.19$ \\
\hline & $3.0 \mathrm{mg}$ & $1.05 \pm 0.12$ & $1.34 \pm 0.18$ & $1.20 \pm 0.45$ & $1.00 \pm 0.05$ & $1.29 \pm 0.36$ & $0.82 \pm 0.34$ \\
\hline \multirow{4}{*}{$\begin{array}{l}\mathrm{SCH} 23390 \\
\quad\left(\mathrm{DR}_{1} \text { antagonist }\right) \\
n=5\end{array}$} & Saline & $0.89 \pm 0.03$ & $1.15 \pm 0.24$ & $1.06 \pm 0.19$ & $1.23 \pm 0.17$ & $1.00 \pm 0.06$ & $1.22 \pm 0.27$ \\
\hline & $5.0 \mu \mathrm{g}$ & $1.13 \pm 0.10$ & $0.79 \pm 0.16$ & $0.70 \pm 0.12$ & $1.59 \pm 0.16^{\star}$ & $1.18 \pm 0.28$ & $0.83 \pm 0.09^{*}$ \\
\hline & $10 \mu \mathrm{g}$ & $1.19 \pm 0.06^{*}$ & $1.19 \pm 0.35$ & $0.89 \pm 0.11$ & $2.28 \pm 0.58^{*}$ & $1.36 \pm 0.37^{\star}$ & $0.95 \pm 0.16^{*}$ \\
\hline & $0.1 \mathrm{mg}$ & $1.17 \pm 0.05^{\star}$ & $0.81 \pm 0.55$ & $0.88 \pm 0.30$ & $1.63 \pm 0.36^{\star}$ & $1.21 \pm 0.24^{*}$ & $0.85 \pm 0.56$ \\
\hline \multirow{4}{*}{$\begin{array}{l}\text { SKF } 38393 \\
\qquad \begin{array}{l}\text { (DR }_{1} \text { agonist) } \\
n=5\end{array}\end{array}$} & Saline & $1.04 \pm 0.03$ & $1.04 \pm 0.03$ & $0.95 \pm 0.11$ & $1.10 \pm 0.02$ & $1.23 \pm 0.09$ & $1.34 \pm 0.31$ \\
\hline & $0.3 \mathrm{mg}$ & $1.16 \pm 0.03$ & $0.94 \pm 0.07$ & $0.97 \pm 0.17$ & $1.47 \pm 0.51$ & $3.41 \pm 0.82$ & $1.46 \pm 0.35$ \\
\hline & $1.0 \mathrm{mg}$ & $1.24 \pm 0.11$ & $1.00 \pm 0.11$ & $1.18 \pm 0.23$ & $2.56 \pm 0.26^{\star \#}$ & $3.74 \pm 1.05$ & $1.34 \pm 0.20$ \\
\hline & $3.0 \mathrm{mg}$ & $1.21 \pm 0.13$ & $1.06 \pm 0.08$ & $1.35 \pm 0.42$ & $2.94 \pm 0.40^{\star \#}$ & $2.47 \pm 0.84$ & $1.42 \pm 0.23$ \\
\hline
\end{tabular}

VA, voiding amplitude of intravesical bladder pressure; VI, voiding interval; NVCs, non-voiding contractions; MA, maximum amplitude of tonic activity; RMS, root mean square; BP, bursting period; all data except for the number of NVCs were normalized to baseline levels to reduce variability for statistics; ${ }^{\star} p<0.05$, ${ }^{* *} p<0.01$ compared with vehicle; $\# p<0.05$ compared with the low dose of drug.

consumption was measured after testing. Based on preliminary observations in CMG and EMG experiments, drugs including the DA precursor L-DOPA $(30 \mathrm{mg} / \mathrm{kg}$, $n=7)$, APO (0.1 mg/kg, $n=7)$, and specific $\mathrm{DR}_{2}$ agonist quinpirole $(0.3 \mathrm{mg} / \mathrm{kg}, n=6)$ were chosen for metabolic cage assays. When L-DOPA was administered, a decarboxylase inhibitor carbidopa ( $3.0 \mathrm{mg} / \mathrm{kg}, 1: 10$ to the dose of L-DOPA) was simultaneously injected to inhibit peripheral production of catecholamines (Celesia and Wanamaker, 1976; Pahwa and Koller, 1996; Stocchi et al., 2015). Saline vehicle or drug solution $(300 \mu \mathrm{l})$ was subcutaneously administered before testing. During the metabolic cage recording, the urine in each void was collected into a small cup filled with $5 \mathrm{ml}$ of mineral oil to prevent urine evaporation, which was resting on a sensor coupled to a force transducer and connected to a computer system. The output of the transducer was recorded and converted to volume with a data acquisition starter kit (DI-159HS, DataQ Instruments) on a computer system for 12 h during daytime. Similarly, the recorded data were later opened in Browser software to calculate the volume per void, $\mathrm{VI}$, voiding frequency and total voided volume. For each rat, each parameter was averaged for statistics. Data were separated into 6- and 12-h increments to determine efficacy of the drugs over time.

\section{Statistics}

Statistical analyses were performed in Prism 7. Because animals exhibited differences in the recovery of bladder and sphincter function after $\mathrm{SCl}$, as well as considerable inter-animal variations in the urodynamic and EUS EMG parameters, the data from CMG and EMG recordings, except for the number of NVCs, were normalized to baseline values in each animal to reduce variability for statistics. Normalized data were analyzed using a Friedman test followed by Dunn's multiple comparisons. A paired $t$ test was used for metabolic cage data. Significance throughout all experiments was set at $p<0.05$. Data are represented as mean \pm SEM

\section{Results}

To specifically identify spinal lumbosacral DAergic mechanisms regulating urinary function, we used an adult rat model with a complete $\mathrm{SCl}$ at the $\mathrm{T10}$ level to remove descending control. Interruption of supraspinal micturition pathways causes acute areflexic bladder paralysis. However, there is usually partial recovery of urinary function via involuntary bladder and urethral reflexes because of the reestablishment of spinal neuronal circuitry that forms in two to three weeks. As the neuronal control of the micturition reflex is restricted within lumbosacral spinal segments, the central neural effects on urination elicited by manipulating DA signaling are likely to originate solely through action on the spinal endogenous DAergic system. Overall, we observed robust changes in the micturition reflex in response to pharmacological blockade or activation of DR.

Before drug administration the most prominent CMG changes detected after $\mathrm{SCl}$ were a higher VA in intravesical pressure (intact $21.4 \pm 1.5$ vs $\mathrm{SCl} 48.7 \pm 1.9 \mathrm{cmH}_{2} \mathrm{O}$, 
A
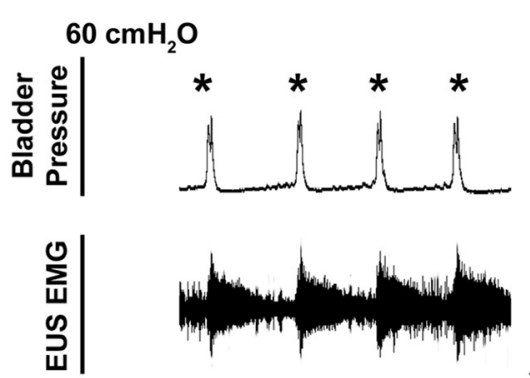

$2.0 \mathrm{mV}$

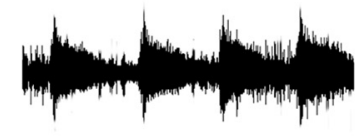

B
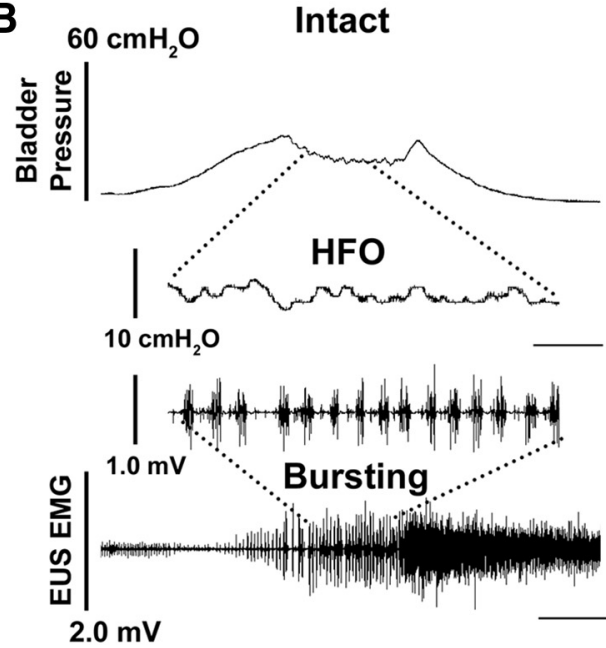

SCI
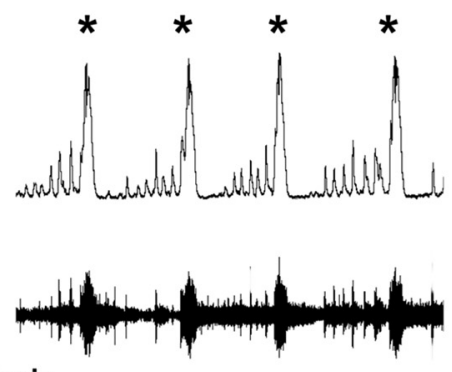

$2.5 \mathrm{~min}$

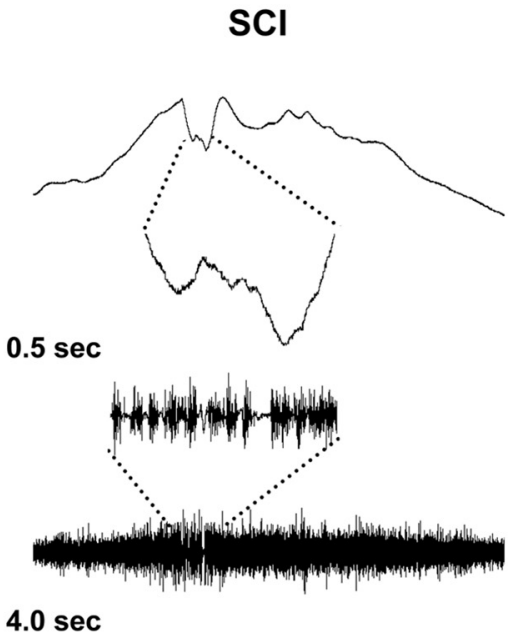

Figure 2. Representative traces show bladder CMG and EUS EMG recordings during continuous bladder filling (0.1 $\mathrm{ml} / \mathrm{min})$ in a neuroaxis intact or $\mathrm{SCl}$ female rat. $\boldsymbol{A}$, The peak amplitude of intravesical pressure (VA) during voiding $\left(^{*}\right)$ is low in the spinal intact rat compared with that in the SCI rat three weeks after T10 spinal transection $(p<0.0001$, unpaired $t$ test) and NVCs are more prominent during the filling phase in the $\mathrm{SCl}$ rat, indicating bladder hyperreflexia. $\boldsymbol{B}$, Time-stretched recordings during voiding show that spinal intact rats exhibit well-coordinated bursting EUS activity and HFOs in bladder pressure during voiding, while this coordination is absent in $\mathrm{SCl}$ rats. Note that the drop in bladder pressure reflects the opening of the urethral outlet. Statistical analysis shows that the duration of EUS bursting activity is shorter $(p<0.001)$ or masked by tonic EUS activity in SCI rats when compared to spinal intact rats.

$p<0.0001$, unpaired $t$ test, $n=6$ per group) during voiding contractions and the emergence of bladder hyperactivity evident as NVCs during bladder filling, compared with spinal intact rats. Additionally, bursting EUS activity during voiding, which consists of a repeating pattern of active periods (APs) and silent periods (SPs), was often absent (two of six SCl rats) or shortened (four of six SCl rats, intact $5.1 \pm 0.4 \mathrm{~s}$ vs SCl $1.2 \pm 0.3 \mathrm{~s}, p<0.001$ ), indicating disorganized coordination of bladder and sphincter activity or DSD (Fig. 2). These findings are similar to what has been reported previously in urethane-anesthetized $\mathrm{SCl}$ rats (Cheng and de Groat, 2004; Chang et al., 2007).

\section{L-DOPA suppresses bladder overactivity and improves detrusor-sphincter coordination}

In the CNS, the enzyme DDC can convert systemically delivered L-DOPA to DA (Wachtel and Abercrombie, 1994; Soares-da-Silva et al., 1997; Park et al., 2014). To observe whether increasing DA synthesis in the caudal spinal cord improves LUT recovery, the DA precursor L-DOPA was administered intravenously during bladder CMG and EUS EMG recordings in rats three weeks after T10 transection. A decarboxylase inhibitor, carbidopa, was simultaneously injected intravenously to inhibit peripheral production of catecholamines. The effect of L-DOPA appeared 5-10 min after administration, and continued for $\sim 25,60$, and $>120 \mathrm{~min}$ in three doses, respectively.

Injections of saline or carbidopa alone did not elicit significant changes in bladder CMG and EUS EMG recordings. However, the three doses of L-DOPA induced a trend of an increased $\mathrm{VI}$ and the high dose significantly reduced the VA of intravesical pressure $(p<0.05$, Friedman test followed by Dunn's; Fig. 3A; Table 1). The low dose of L-DOPA $(1.0 \mathrm{mg} / \mathrm{kg})$ triggered bursting EUS activity during voiding when it was initially absent, and also caused a non-significant prolongation of EUS bursting activity if it was present before drug delivery. The middle and high doses of L-DOPA (10 and $30 \mathrm{mg} / \mathrm{kg}$ ) significantly reduced the maximum amplitude (both $p<0.05$ ) and RMS level 
A

Saline
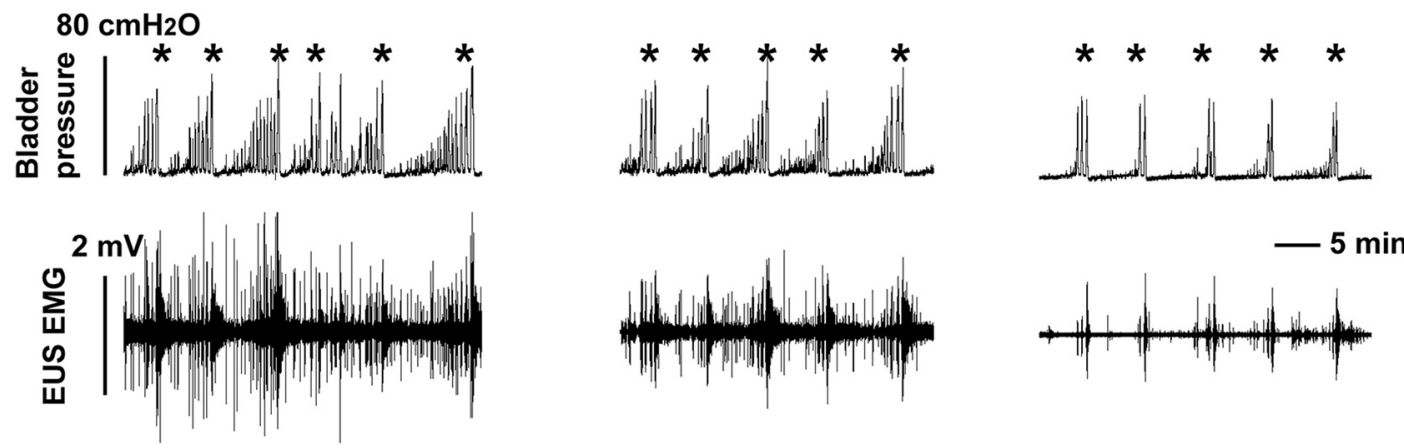

B

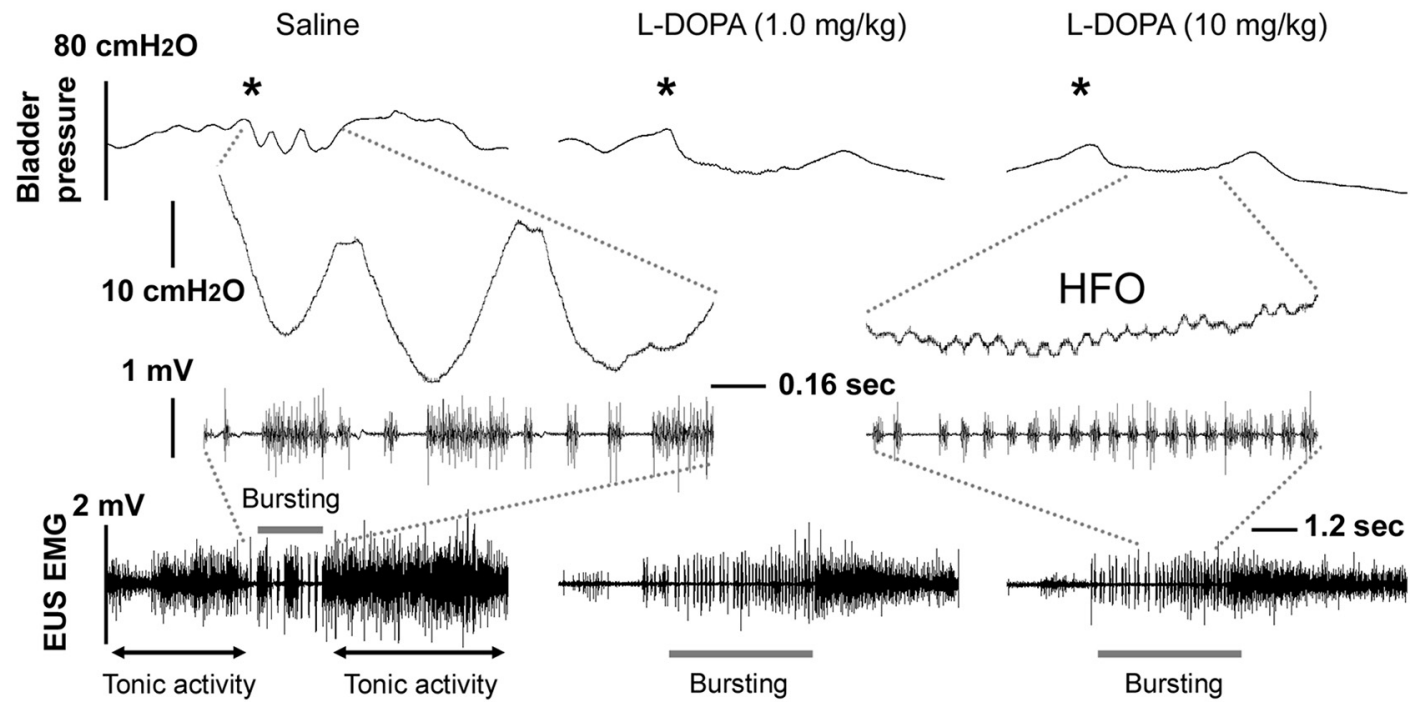

Figure 3. Representative traces show that L-DOPA suppresses bladder overactivity and improves detrusor-sphincter coordination following SCl. Three weeks following a complete T10 spinal cord transection, different concentrations of L-DOPA are administered intravenously during bladder CMG and sphincter EMG recordings. $\boldsymbol{A}$, Time-compressed traces show that following SCI, control recordings after intravenous administration of vehicle (saline) exhibit numerous large amplitude NVCs before the voiding contraction (marked by *) that are accompanied by large amplitude tonic EUS EMG activity. Administration of L-DOPA to the same animal induces dose-dependent changes in reflex LUT function, including decreased amplitude of voiding contractions (VA), a reduction in the number and amplitude of NVCs, and lowered tonic EUS activity. $\boldsymbol{B}$, Time-expanded traces of bladder contractions and EUS EMG activity show that DSD, which typically manifests as the lack of detrusor HFOs and irregular and short EUS bursting periods (gray lines) occurs in control recordings after intravenous administration of vehicle. However, injection of L-DOPA unmasks HFOs in bladder pressure and induces a longer and more regular EUS bursting period during voiding, as shown in the 0.16-s-scaled expanded view. EUS tonic activity (two-headed arrows) that occurs in the filling phase and after voiding in the control recording is remarkably reduced. Notably, after L-DOPA administration, detrusor and sphincter activity exhibits better coordination during voiding ( ${ }^{*}$ indicating voiding contractions). All recordings are from the same experiment.

(mid dose $p<0.05$, high dose $p<0.001$ ) of EUS tonic activity, and the high dose significantly increased the duration of bursting activity during voiding and the associated bladder high-frequency oscillations (HFOs; Fig. 3B). Consequently, APs and SPs were more regular during bursting (Fig. 3B) similar to that which was seen in intact rats (Chang et al., 2007), indicating better coordinated detrusor-sphincter activity. In addition, the number of bladder NVCs per voiding cycle was decreased after drug administration which was significant in the high dose $(p<0.05$; Fig. $3 A, B)$.

To verify that the effects of L-DOPA were mediated via spinal $D R$, two specific $D R_{1 / 2}$ antagonists were administered following the high dose of L-DOPA. When SCH 23390, a DR 1 antagonist $(0.1 \mathrm{mg} / \mathrm{kg}, 100 \mu \mathrm{l}$, i.v.), was injected $(n=3)$, the VA of bladder contractions increased 2.1-fold and the frequency of NVCs was also enhanced 2.7-fold (both $p<0.05$, paired $t$ test). The drug enhanced EUS tonic activity during the filling phase (Fig. 4A), producing a 3.3-fold increase in EUS RMS levels $(p<0.001)$ and suppressed the L-DOPA enhancement of bladder HFOs and EUS bursting that occurred during voiding, resulting in the re-emergence of DSD (Fig. 4B). Injection of remoxipride $(3.0 \mathrm{mg} / \mathrm{kg}, 100 \mu \mathrm{l})$, a $\mathrm{DR}_{2}$ antagonist, in L-DOPA treated rats slightly increased RMS levels of EUS tonic activity 1.35 -fold ( $p>0.05, n=3$ ), but did not obviously 
A
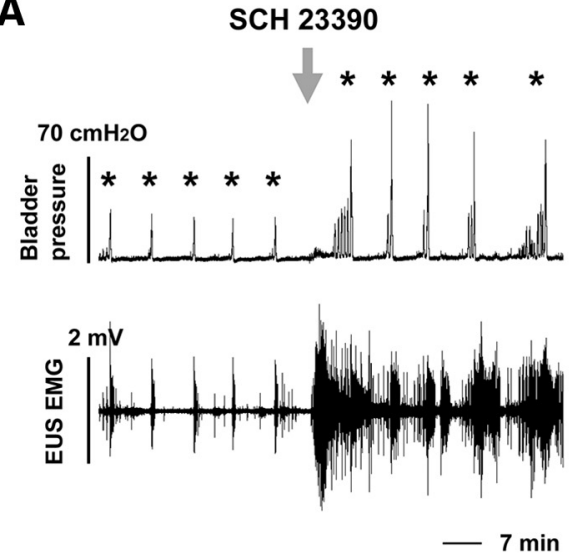

C
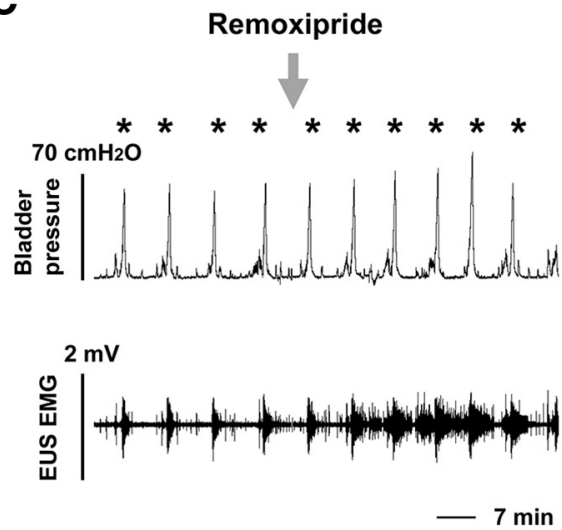

B
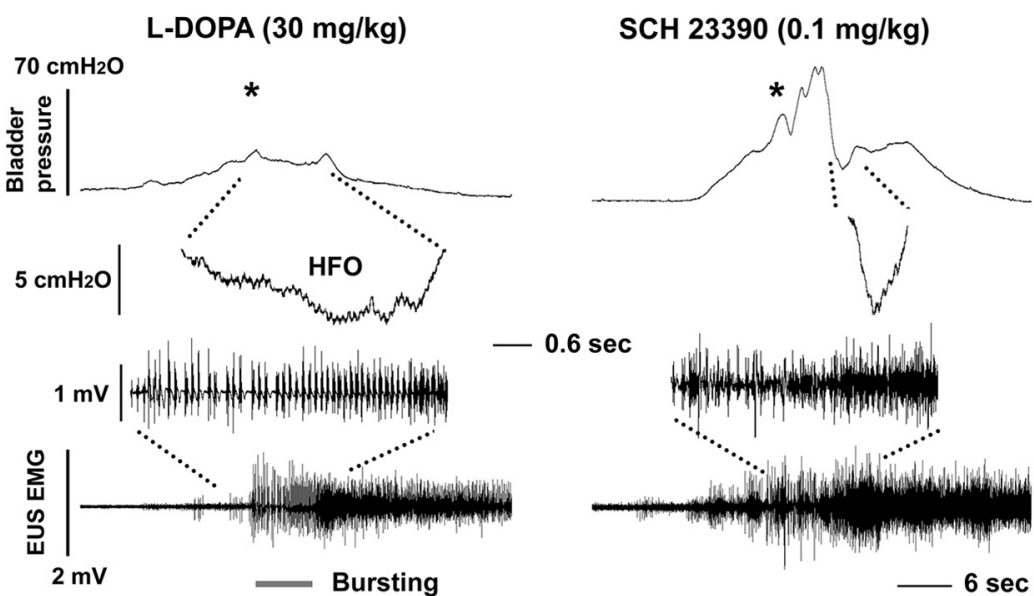

D

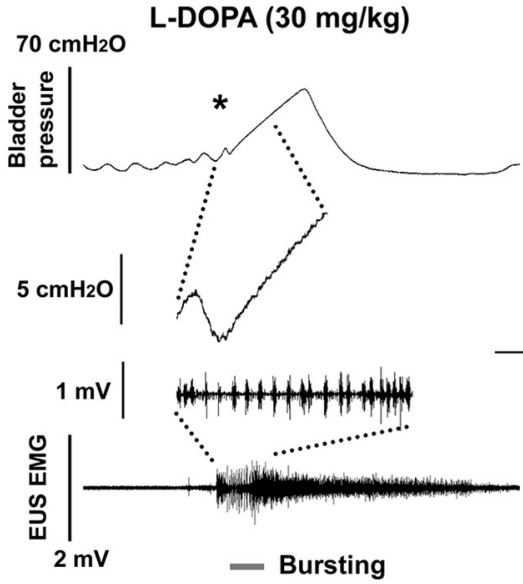

Remoxipride $(3.0 \mathrm{mg} / \mathrm{kg})$
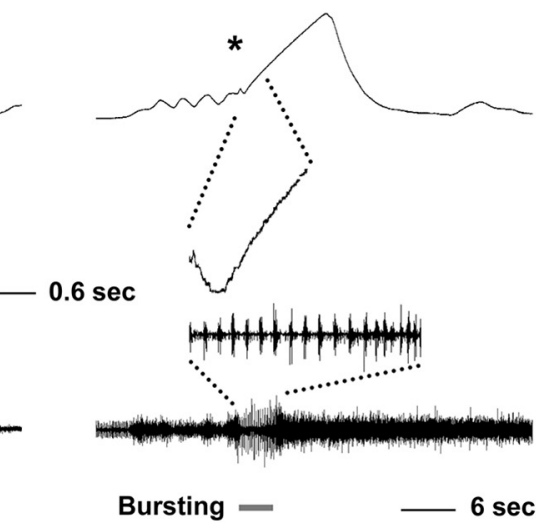

Figure 4. Blocking spinal DRs in SCl rats diminishes the effects of L-DOPA on bladder and EUS reflexes. Recordings in $\boldsymbol{A}, \boldsymbol{B}$ and $\boldsymbol{C}$, $\boldsymbol{D}$ are from two different experiments. $\boldsymbol{A}$, The left side of the traces show repetitive voiding in a $\mathrm{SCl}$ rat consisting of low amplitude bladder contractions and synchronized bursts of EUS EMG activity following sequential injections of L-DOPA (0.1, 10, and $30 \mathrm{mg} / \mathrm{kg}$ ). Injection of SCH $23390\left(0.1 \mathrm{mg} / \mathrm{kg}\right.$, down arrow), which blocks DR ${ }_{1}$, increases the VA to similar levels as seen during basal recordings and increases the number of NVCs. In parallel, EUS tonic activity during the filling phase is remarkably elevated. $\boldsymbol{B}$, Time-expanded views of two voiding responses from the recording in panel $\boldsymbol{A}$. The traces on the left show HFOs in intravesical pressure and EUS bursting (gray lines) after administration of L-DOPA. The top and bottom traces are from the same time base and time expanded sections of these traces are shown in the middle. The traces on the right are organized in the same manner and show that SCH 23390 reverses the effects of L-DOPA by blocking HFOs and EUS bursting and increasing tonic EUS activity and the VA. HFOs and EUS bursting are reduced in duration or disappear after inhibiting $\mathrm{DR}_{1}$ with $\mathrm{SCH}$ 23390 (right traces). $\boldsymbol{C}, \boldsymbol{D}$, The records are from the same experiment and organized as described in panels $\boldsymbol{A}, \boldsymbol{B}$. Recordings at a slow time base $(\boldsymbol{C})$ show that in a $\mathrm{SCl}$ rat treated with L-DOPA, administration of remoxipride $(3.0 \mathrm{mg} / \mathrm{kg})$, a $\mathrm{DR} \mathrm{R}_{2}$ antagonist, increased EUS tonic activity to a level that is similar to what occurred in basal recordings but did not obviously influence bladder contractions, detrusor HFOs, or EUS bursting during voiding as shown in the time expanded view (D). These data indicate that L-DOPA improves LUT performance via mechanisms involving spinal $\mathrm{DR}_{1}$ and $\mathrm{DR}_{2}$ in $\mathrm{SCl}$ rats (* indicating voiding contractions).

influence the bladder VA, detrusor HFO or EUS bursting during voiding (Fig. $4 C, D$; Table 2). This indicates that enhancing spinal DA signaling with L-DOPA can inhibit bladder hyperactivity and reduce DSD to achieve better coordinated bladder-sphincter activity, thereby improving LUT performance following SCl.

\section{APO improves bladder and EUS voiding reflexes}

The non-selective DR agonist APO, which was administered intravenously in three increasing doses sequentially (5-100 $\mu \mathrm{g} / \mathrm{kg}, n=6$ experiments; Table 1) during bladder
CMG and sphincter EMG assessments, elicited rapid onset effects that continued for $\sim 20,45$, and $>100$ min following the three doses, respectively. On average, the low dose $(5.0 \mu \mathrm{g} / \mathrm{kg})$ in two rats, which did not exhibit EUS bursting during baseline, unmasked bursting and significantly increased the VA in intravesical pressure $(p<0.05$, Friedman test followed by Dunn's). However, neither the middle nor high dose increased the VA but the high dose significantly decreased the number of NVCs (Table 1). Meanwhile, the middle dose $(10 \mu \mathrm{g} / \mathrm{kg})$ decreased the RMS value of EUS tonic activity in the filling phase $(p<0.01)$, 
Table 2: Summary of agonist-antagonist interactions on EUS function.

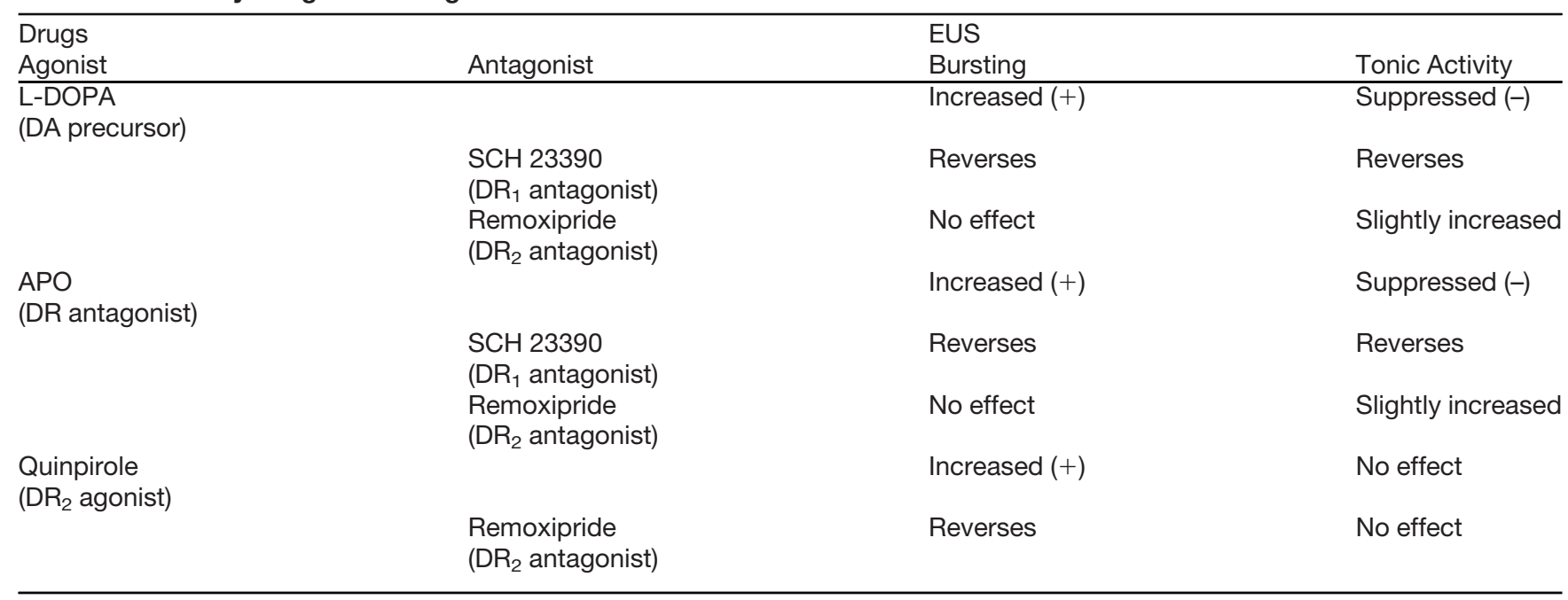

whereas the high dose $(0.1 \mathrm{mg} / \mathrm{kg})$ caused a reduction in RMS values $(p<0.05)$ and maximum amplitude $(p<0.01)$ of EUS tonic activity. Notably, the duration of bursting EUS activity and accompanied bladder HFOs during voiding were significantly $(p<0.05)$ prolonged after the high dose of APO, indicating the facilitation of voiding reflexes (Fig. 5).

To examine the role of spinal DR in the effects of APO, two specific DR antagonists, SCH $23390\left(\mathrm{DR}_{1}: 0.1 \mathrm{mg} / \mathrm{kg}\right.$, $100 \mu \mathrm{l})$ or remoxipride $\left(\mathrm{DR}_{2}: 3.0 \mathrm{mg} / \mathrm{kg}, 100 \mu \mathrm{l}\right)$, were administered, respectively, following the high dose of APO. $\mathrm{SCH} 23390(n=3)$ did not change the VA or the frequency of NVCs, while the RMS value of EUS tonic activity was elevated 2.7 -fold ( $p<0.001$, paired $t$ test) during the filling phase; EUS bursting during voiding, which APO enhanced, disappeared and DSD reemerged. Remoxipride $(n=3)$ reduced the VA 0.86 -fold $(p<0.05)$ and non-significantly increased the RMS value of EUS tonic activity 1.18-fold, but did not significantly influence bursting during voiding (Table 2). The results were similar to those obtained when the drugs were administered after L-DOPA. Thus, non-selective stimulation of spinal DR with APO suppresses bladder overactivity and DSD to improve bladder storage and voiding reflexes in SCI rats.

\section{Blockage of spinal $\mathrm{DR}_{2}$ does not significantly influence bladder and EUS reflexes}

To determine whether tonic activation of spinal $\mathrm{DR}_{2}$ by endogenous DA modulates bladder and EUS reflexes after $\mathrm{SCl}$, we intravenously injected three doses $(0.1,1.0$, and $3.0 \mathrm{mg} / \mathrm{kg}$ ) of remoxipride, a specific $\mathrm{DR}_{2}$ antagonist, sequentially at 30-min intervals during continuous bladder CMG and EUS EMG recordings (Table 1). The drug did not induce significant changes in any parameters. For those that initially lacked bursting EUS activity during voiding cycles, remoxipride did not unmask the activity. For those exhibiting EUS bursting and bladder HFO, none of the three doses shortened or masked this pattern. Therefore, the results suggest that spinal $\mathrm{DR}_{2}$ do not play a tonic role in recovered bladder and EUS reflexes in $\mathrm{SCl}$ rats.

\section{Stimulating spinal $\mathrm{DR}_{\mathbf{2}}$ increases the duration of EUS bursting}

To examine the effect of spinal $\mathrm{DR}_{2}$ activation on the micturition reflex, we intravenously injected increasing doses of quinpirole, a specific $\mathrm{DR}_{2}$ agonist, at 30-min intervals during continuous infusion $\mathrm{CMG}$ and EUS EMG recordings (Table 1). The effect of quinpirole appeared within 1-2 min after administration, and continued for $\sim 15,25$, and $35 \mathrm{~min}$ as the dose increased. Compared with vehicle delivery, the middle dose of quinpirole increased the VA of bladder contractions $(p<0.05$, Friedman test followed by Dunn's) and all three doses increased the VI (all $p<0.05$; Fig. 6A). Quinpirole did not influence EUS tonic activity in the filling phase but the low and middle doses markedly (both $p<0.05$ ) increased the duration of EUS bursting during voiding. In expanded recordings, it is clear in basal conditions or after vehicle treatment that the AP and SP components of EUS bursting were irregular and bladder HFOs were not prominent. However, after administration of quinpirole, EUS bursting exhibited a regular pattern (Fig. 6B). Following the last dose of quinpirole, administration of remoxipride $(3.0 \mathrm{mg} /$ $\mathrm{kg}, 100 \mu \mathrm{l}, n=4)$ reduced the VA of bladder contractions by 0.76 -fold ( $p<0.05$, paired $t$ test). Notably, the drug also masked EUS bursting by increasing high-amplitude tonic activity during voiding (Fig. 6C; Table 2). This confirms that the effects of quinpirole were specifically induced by stimulation of $\mathrm{DR}_{2}$. Therefore, the results indicate that activation of spinal $\mathrm{DR}_{2}$ enhances EUS bursting activity to improve voiding in the recovered micturition reflex.

\section{Manipulating spinal $\mathrm{DR}_{\mathbf{1}}$ increases EUS tonic activity}

Sequential administration of increasing doses of the selective DR 1 antagonist SCH 23390 (5.0, 10, $100 \mu \mathrm{g} / \mathrm{kg}$, i.v.), rapidly altered bladder and EUS activity (Fig. 7). The effects persisted for $\sim 20,35$ and $75 \mathrm{~min}$ in a dosedependent manner. The VA of intravesical pressure in bladder contractions was significantly (both $p<0.05$, Friedman test followed by Dunn's) increased in response 
A

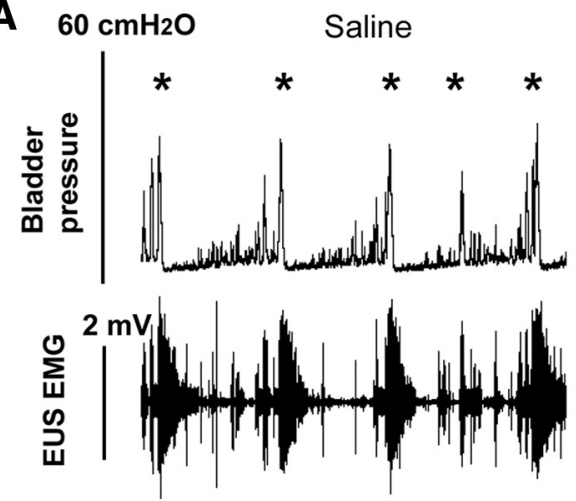

B
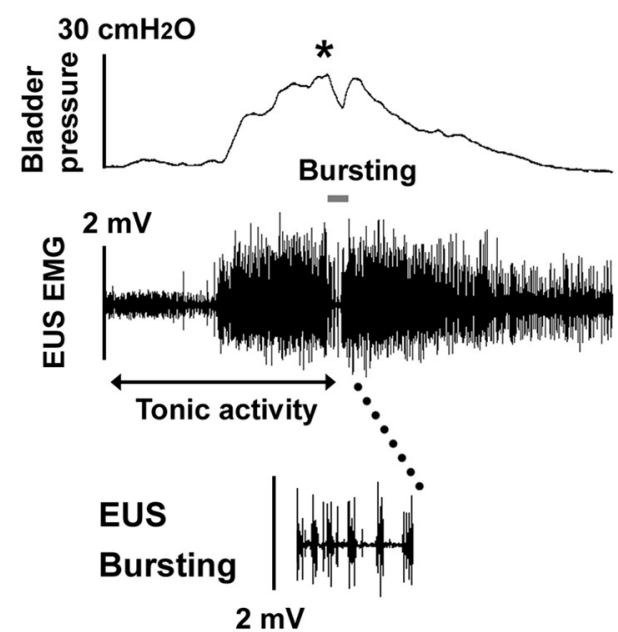
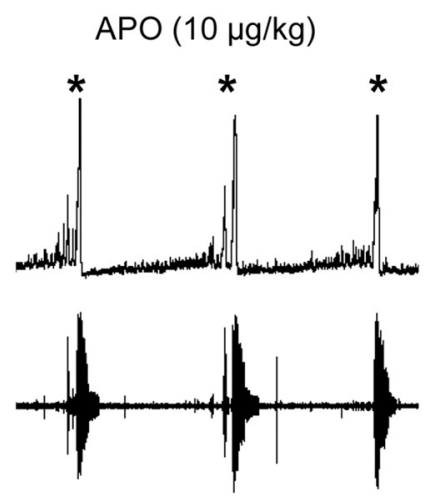

APO $(10 \mu \mathrm{g} / \mathrm{kg})$
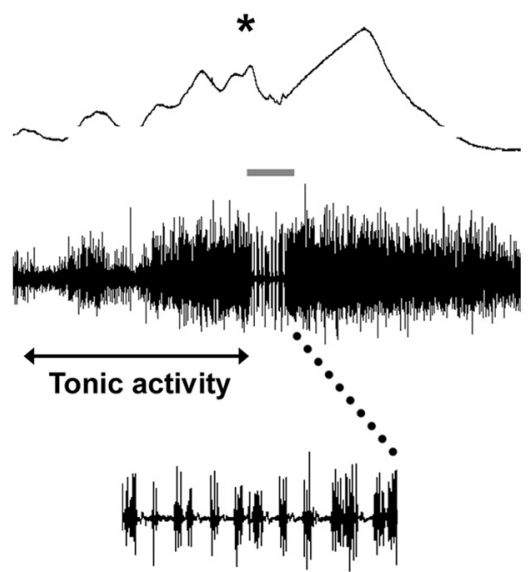

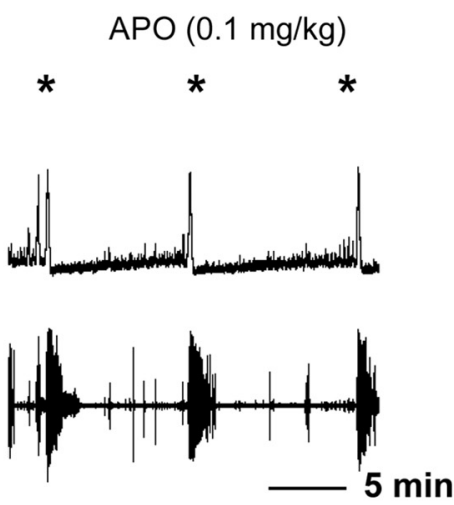

APO $(0.1 \mathrm{mg} / \mathrm{kg})$
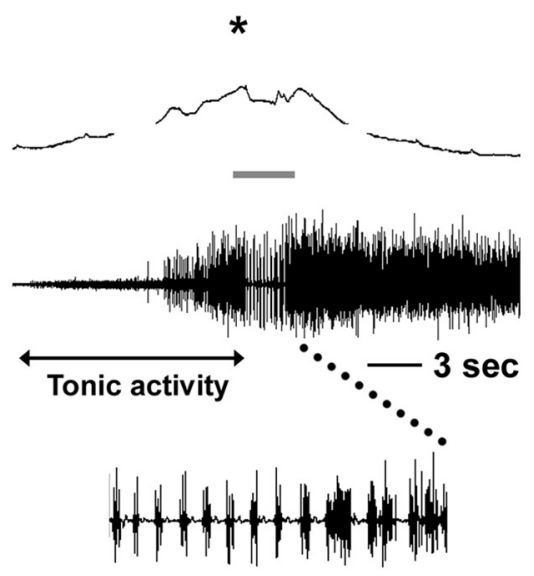

$-0.6 \mathrm{sec}$

Figure 5. Representative traces show that non-selective activation of spinal DR with APO reduces the number of NVCs, lengthens the $\mathrm{VI}$ and enhances the duration of EUS EMG bursting in a SCI rat. A, After vehicle (saline) delivery, many NVCs occur during the filling phase and are accompanied by high amplitude tonic EUS activity. EUS activity also increases during and after voiding (marked by *). Administration of APO $(10 \mu \mathrm{g} / \mathrm{kg}$, i.v.) reduces the number of NVCs, decreases tonic EUS activity and increases the VA. The higher dose $(0.1 \mathrm{mg} / \mathrm{kg})$ reverses the effects on the VA but maintains suppression of NVCs. B, In a time-expanded view, stimulating DR with APO reduces the amplitude of EUS tonic activity before voiding (two-headed arrows) and increases the duration of EUS bursting during voiding contractions (gray lines), indicating the facilitation of voiding. A higher dose $(0.1 \mathrm{mg} / \mathrm{kg})$ of APO elicited slightly larger effects. A time-expanded view of the EUS bursting period is shown in panel $\boldsymbol{B}$.

to the middle and high doses of the drug. All three doses increased the RMS value of EUS tonic activity in the filling phase before voiding onset (all $p<0.05$ ) and shortened the EUS bursting period during voiding (both $p<0.05$ in the low and middle doses; $p=0.064$ in the high dose; Table 1). Notably, the EUS bursting pattern accompanied by bladder HFOs which initially existed in two rats was masked by tonic activity after the middle and high doses of the drug were delivered. This suggests that the physiological role of spinal $D_{1}$ is active suppression of tonic EUS muscle activity in $\mathrm{SCl}$ rats. Since the EUS tonic phase before bursting reflects the closure of the urethral outlet for urine storage, it is therefore considered that activation of spinal $\mathrm{DR}_{1}$ reduces outlet resistance and facilitates voiding. Thus, the observed elevation of VA of bladder contractions after blocking these receptors could reflect an increase in outlet resistance. In addition, spastic movements of the body and legs occurred when the middle and high doses of $\mathrm{SCH}$ 23390 were administered, indicating similar $D_{1}$ inhibitory mechanisms in spinal motor pathways controlling somatic muscles. Collectively, blocking spinal $\mathrm{DR}_{1}$ inhibits the voiding reflex following SCl.

Surprisingly, stimulation of spinal $\mathrm{DR}_{1}$ with SKF 38393 (0.3, $1.0,3.0 \mu \mathrm{g} / \mathrm{kg}$ ), a specific $\mathrm{DR}_{1}$ agonist, induced similar responses in EUS muscle activity. The effect appeared rapidly after administration and continued for $\sim 20,35$, and $70 \mathrm{~min}$ after sequential administration of each of the three doses. The middle and high doses of the drug increased (both $p<0.05$, Friedman test followed by Dunn's) the RMS value of EUS tonic activity during the filling phase (Fig. 8). No significant effect was observed on bladder activity.

\section{Manipulating spinal DR affects voiding efficiency}

During single CMGs which were used to evaluate voiding efficiency, the high dose of L-DOPA plus carbidopa induced a non-significant increase in the voiding volume $(p=0.077$, Friedman test followed by Dunn's), significantly 
A
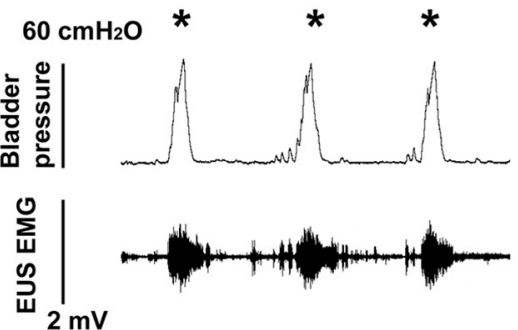

B

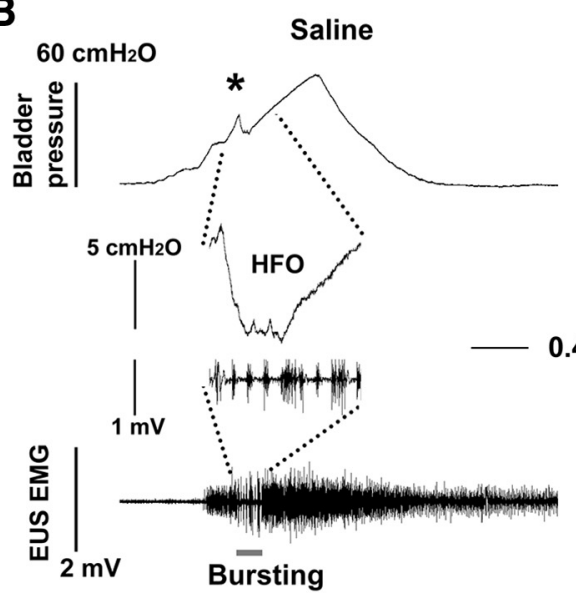

C

\section{Quinpirole Remoxipride}

$(0.3 \mathrm{mg} / \mathrm{kg}) \quad(3.0 \mathrm{mg} / \mathrm{kg})$
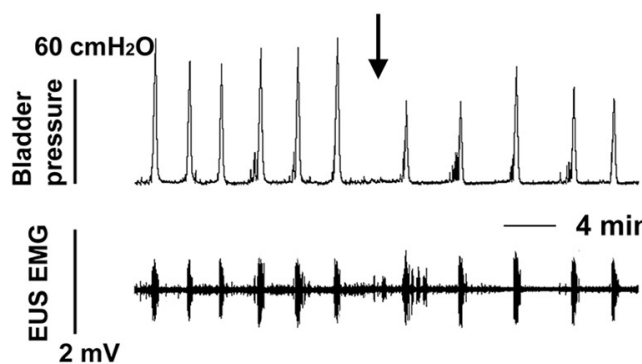

Quinpirole $(30 \mu \mathrm{g} / \mathrm{kg})$
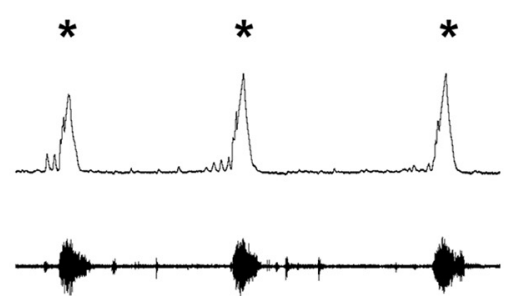

$0.4 \mathrm{sec}$

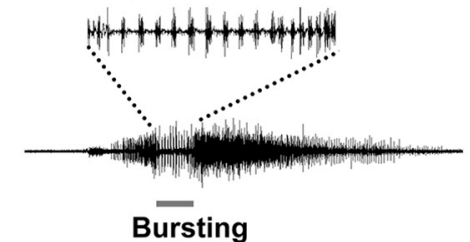

Quinpirole

$(0.3 \mathrm{mg} / \mathrm{kg})$
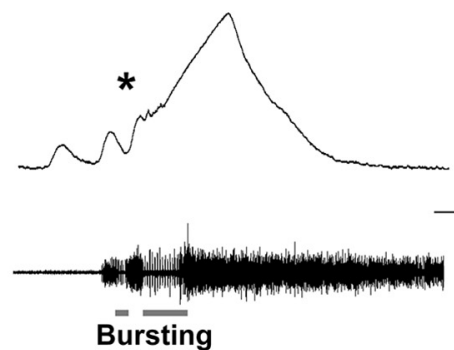

Quinpirole $(0.1 \mathrm{mg} / \mathrm{kg})$
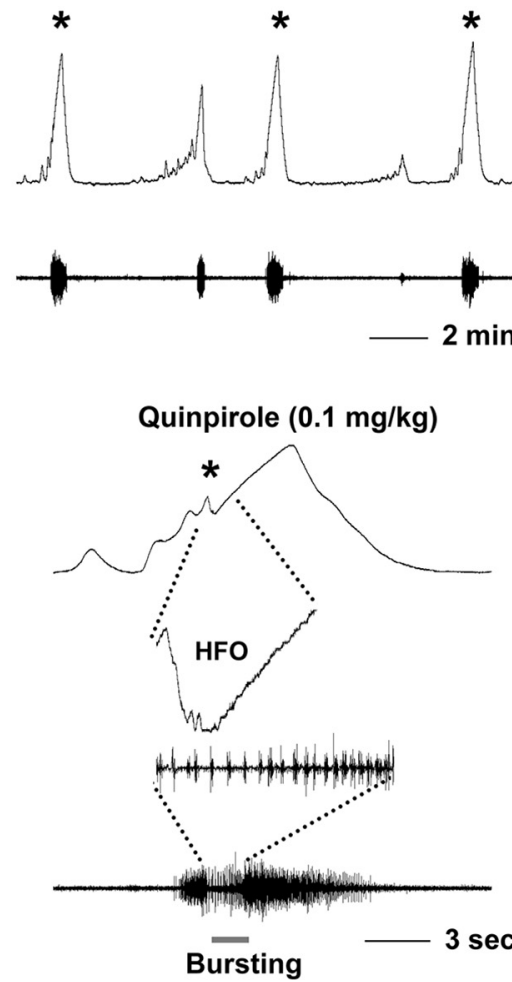

Remoxipride

(3.0 $\mathrm{mg} / \mathrm{kg}$ )

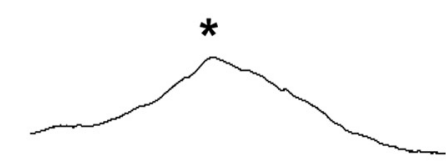

$3 \mathrm{sec}$

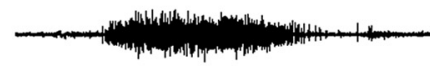

No Bursting

Figure 6. Selective stimulation of spinal $\mathrm{DR}_{2}$ increases bladder capacity and improves voiding reflexes. $\boldsymbol{A}$, Three weeks after a $\mathrm{T} 10$ spinal cord transection, control CMG and EUS EMG recordings during continuous bladder filling and after intravenous saline injections exhibited tonic EUS activity between repeated reflex bladder contractions and voiding (marked by *). Intravenous injections of quinpirole, a $\mathrm{DR}_{2}$ agonist $(10 \mu \mathrm{g}$ or $0.1 \mathrm{mg} / \mathrm{kg})$, prolonged the $\mathrm{VI}$ and reduced EUS tonic activity during bladder filling. $\boldsymbol{B}$, In a timeexpanded view, the phasic bursting of EUS during voiding in $\mathrm{SCl}$ rats is short and irregular in the control recording following an injection of saline. However, after administration of quinpirole, EUS bursting is prolonged and more regular although bladder pressure oscillation patterns (HFOs) do not change (* indicating the onset of voiding). C, Following the high dose of quinpirole, administration of remoxipride $(3.0 \mathrm{mg} / \mathrm{kg})$ suppresses the large amplitude voiding reflex in bladder activity and masks EUS bursting during voiding.

reduced residual volume (saline $1.15 \pm 0.25$ vs high dose $0.79 \pm 0.12, p<0.05)$, and increased voiding efficiency (saline $0.97 \pm 0.14$ vs high dose $1.56 \pm 0.30, p<0.05$ ). Bladder capacity did not change with any doses (Fig. 9A). Carbidopa alone did not induce a change in any urodynamic parameters (Fig. 9B). The high dose of APO significantly increased the voiding volume (saline $0.84 \pm 0.15$ vs high dose $1.26 \pm 0.20$ ), reduced residual urine (saline $0.79 \pm 0.01$ vs high dose $0.36 \pm 0.18$ ) and enhanced voiding efficiency (saline $0.98 \pm 0.14$ vs high dose $1.79 \pm 0.06$, all $p<0.05)$. Although no changes were induced by the low and mid doses, there was a trend revealing an increase in the voiding volume and voiding efficiency as well as a decrease in the residual volume. Bladder capacity did not change with all three doses (Fig. 9C).

Remoxipride did not alter any voiding parameter (Fig. $9 D$ ). However, the high dose of quinpirole significantly improved voiding efficiency (saline vehicle $0.85 \pm 0.09$ vs hgh dose $2.12 \pm 0.82, p<0.05$ ), reduced residual volume (saline $1.52 \pm 0.38$ vs high dose $0.37 \pm 0.04$ ), and induced 
A

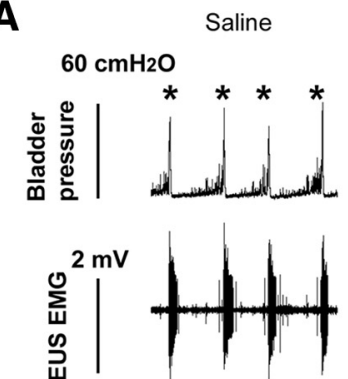

B

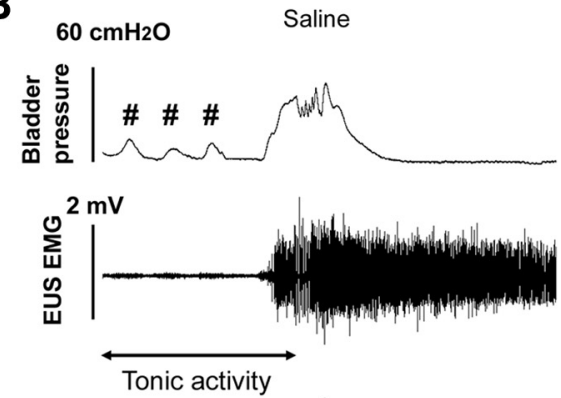

C

Saline

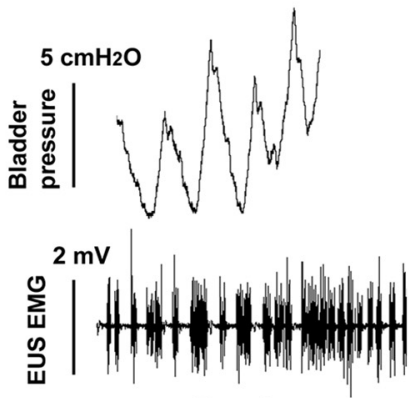

Bursting
$\mathrm{SCH} 23390(10 \mu \mathrm{g} / \mathrm{kg})$
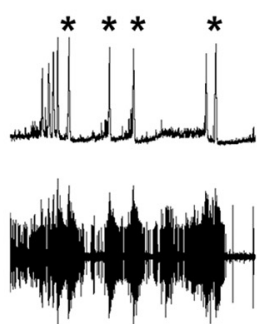

$\mathrm{SCH} 23390(0.1 \mathrm{mg} / \mathrm{kg})$
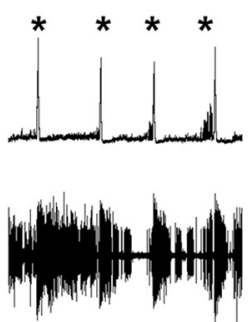

$-5 \mathrm{~min}$

$\mathrm{SCH} 23390(10 \mu \mathrm{g} / \mathrm{kg})$
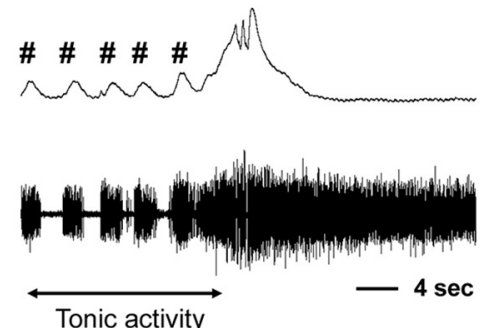

$\mathrm{SCH} 23390(10 \mu \mathrm{g} / \mathrm{kg})$
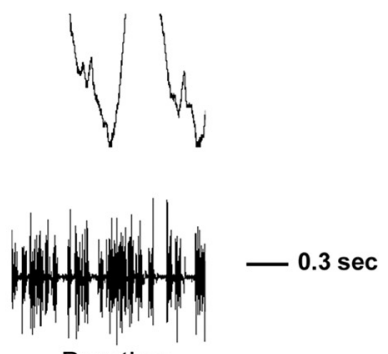

Bursting

Figure 7. Inhibition of spinal $\mathrm{DR}_{1}$ increases tonic EUS activity in SCl rats. $\boldsymbol{A}$, Traces show that after different doses of $\mathrm{SCH} 23390(10 \mu \mathrm{g}$ and $0.1 \mathrm{mg} / \mathrm{kg}$ ) were delivered to block spinal $\mathrm{DR}_{1}$ during bladder $\mathrm{CMG}$ and sphincter EMG recordings, EUS tonic activity robustly increases and the VA of bladder contractions slightly elevates (* indicating voiding contractions). $\boldsymbol{B}$, In a time-expanded view, EUS tonic activity (twoheaded arrows) in response to bladder NVCs (\#) in the filling phase is greater following SCH $23390(10 \mu \mathrm{g} / \mathrm{kg})$ injections than in the control recording after saline injections. $\boldsymbol{C}$, Blocking $\mathrm{DR}_{1}$ results in a shorter EUS bursting period compared to vehicle injections. There is still a lack of high-frequency detrusor oscillations during voiding (traces in $\boldsymbol{C}$ are an expanded portion of voiding with bursting in $\boldsymbol{B}$ ). Therefore, this suggests that spinal $\mathrm{DR}_{1}$ regulate the micturition reflex following $\mathrm{SCl}$ and that they are mainly involved in the regulation of EUS activity that serves to facilitate urine elimination.

a non-significant increase in the voiding volume $(p=$ 0.077). Bladder capacity was not affected at any dose (Fig. 9E). Meanwhile, SKF 38393 did not affect any parameter in the voiding efficiency tests (Fig. 9F). In contrast, SCH 23390 significantly reduced the voiding efficiency with middle and high doses (saline $1.28 \pm 0.23$ vs mid dose $0.77 \pm 0.19$, high dose $0.54 \pm 0.23$, both $p<0.05$ ) and triggered a non-significant decrease in the voiding volume and an increase in residual volume. Bladder capacity did not change with any of the three doses (Fig. 9G).

\section{Stimulating $\mathrm{DR}_{\mathbf{2}}$ improves spontaneous voiding in $\mathrm{SCl}$ rats}

Animals were placed in metabolic cages to measure voided volume and frequency of spontaneous micturition three weeks after SCl. Drugs [L-DOPA $(30 \mathrm{mg} / \mathrm{kg}$, with carbidopa $3.0 \mathrm{mg} / \mathrm{kg})$, APO $(0.1 \mathrm{mg} / \mathrm{kg})$ and quinpirole $(0.3 \mathrm{mg} / \mathrm{kg})]$ dissolved in $300 \mu \mathrm{l}$ of saline were administered subcutaneously before the recording. Compared with vehicle delivery, water consumption was not significantly different after administration of each of the three drugs (data not shown). In consideration of the relatively short duration of drug effects, micturition parameters were examined during the first $6 \mathrm{~h}$ after drug/vehicle delivery to evaluate peak effects. Statistical analyses revealed that following subcutaneous injection of L-DOPA, the most apparent effect was prolonged $\mathrm{VI}$ (saline 77.6 \pm 7.5 vs L-DOPA $116 \pm 18.5 \mathrm{~min}$, paired $t$ test, $p<0.05$ ) while neither the volume per void nor total voiding volume within 


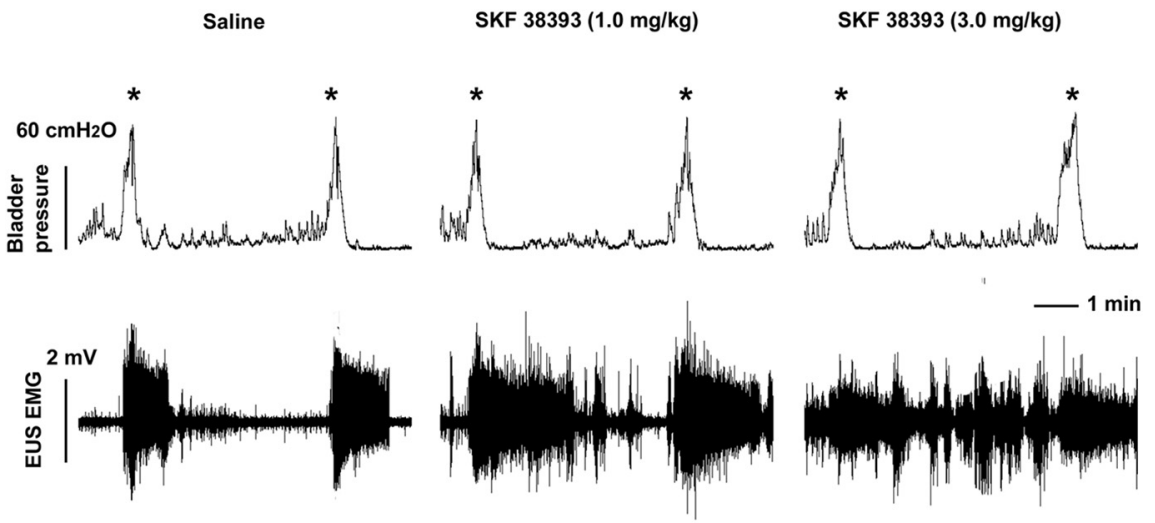

Figure 8. Selective stimulation of spinal $\mathrm{DR}_{1}$ increases tonic EUS activity in SCI rats. Following administration of saline during a continuous bladder CMG and EUS EMG recordings, voiding occurs at regular intervals and is associated with EUS bursting followed by tonic EUS EMG activity. Low level tonic EUS activity occurs between voids. After administration of either the mid (1.0 mg/kg) or high $(3.0 \mathrm{mg} / \mathrm{kg})$ dose of SKF 38393, a DR 1 agonist, EUS tonic activity increases during the period between voids (* indicates voiding contractions). As evident in the representative traces, the agonist has no effect on the VI or VA of voiding contractions.

$6 \mathrm{~h}$ significantly changed when compared to vehicle delivery (Fig. 10A). This suggests that elevation of spinal DA signaling may improve urine storage for recovered spontaneous micturition function in $\mathrm{SCl}$ rats.

When APO was administered to non-selectively activate $D R$, it, unexpectedly, did not cause significant changes in any micturition parameters (Fig. 10B). In contrast, administration of quinpirole to stimulate $D_{2}$ induced a robust increase in the volume per void (saline $1.4 \pm 0.2$ vs quinpirole $2.1 \pm 0.2 \mathrm{ml}, p<0.01$ ) and total voiding volume during the recording period (saline $4.7 \pm 0.7$ vs quinpirole $15.1 \pm 3.0 \mathrm{ml}, p=0.013$ ). In addition, there were significantly shortened VI (saline $89.6 \pm 7.8$ vs quinpirole $60.1 \pm 11 \mathrm{~min}$ ) which reflected an elevation in voiding frequency (Fig. 10C). Since there were no differences detected in water intake between vehicle and drug delivery, the observed increase in the voiding volume is due to drug effects and not an increased consumption of water during the recording. Thus, specifically stimulating spinal $\mathrm{DR}_{2}$ with quinpirole may enhance
A

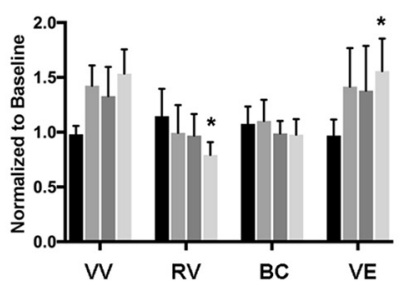

D

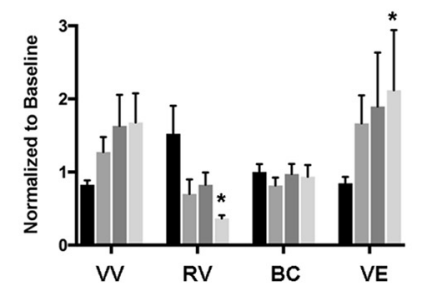

B

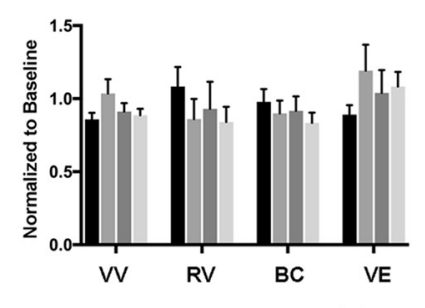

E

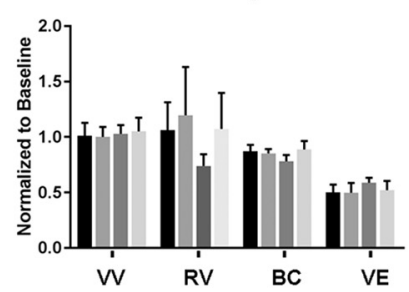

C

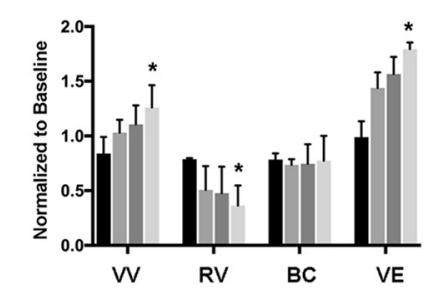

F

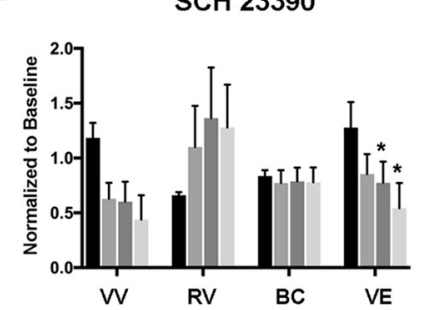

G

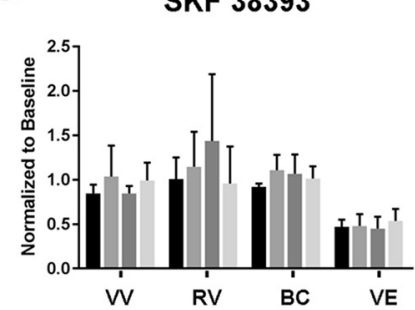

Figure 9. Effects of drugs that modulate DAergic mechanisms on LUT storage and voiding function in SCI rats. Drugs including L-DOPA (with carbidopa), carbidopa, APO, remoxipride, quinpirole, SKF 38393, and SCH 23390 were administered cumulatively during single CMG recordings in a range of doses that are listed in Table 1. The high dose of L-DOPA plus carbidopa $(\boldsymbol{A})$ induces a non-significant increase in the voiding volume (V), significantly reduces the residual volume (RV), and increases the voiding efficiency (VE; both ${ }^{*} p<0.05$, Friedman test followed by Dunn's). Bladder capacity (BC) does not change with any dose. Carbidopa alone (B) does not induce any changes in voiding parameters $(p>0.05)$. Administration of the high dose of either APO, a non-selective DR agonist $(\boldsymbol{C})$, or quinpirole $(\boldsymbol{D})$, a selective $\mathrm{DR} \mathrm{R}_{2}$ agonist, elicits effects similar to that of L-DOPA. Blocking $\mathrm{DR}_{1}$ with the mid or high dose of SCH $23390(\boldsymbol{F})$ significantly reduces voiding efficiency (both ${ }^{*} p<0.05$ ). However, inhibiting $\mathrm{DR}_{2}$ with remoxipride $(\boldsymbol{E})$ or stimulating $\mathrm{DR}_{1}$ with $\mathrm{SKF} 38393(\boldsymbol{G})$ does not alter voiding efficiency. 
A

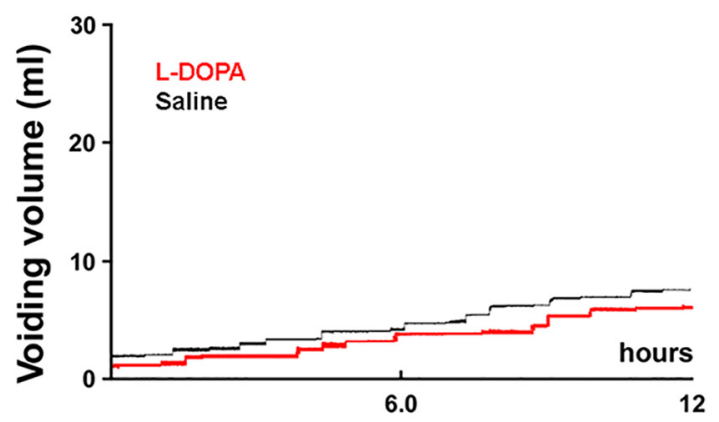

B

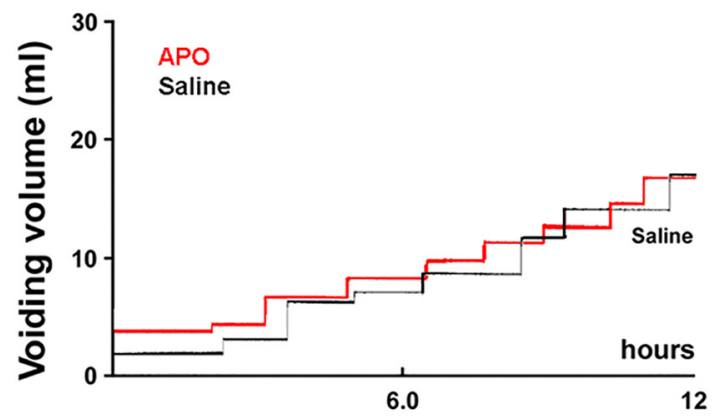

C

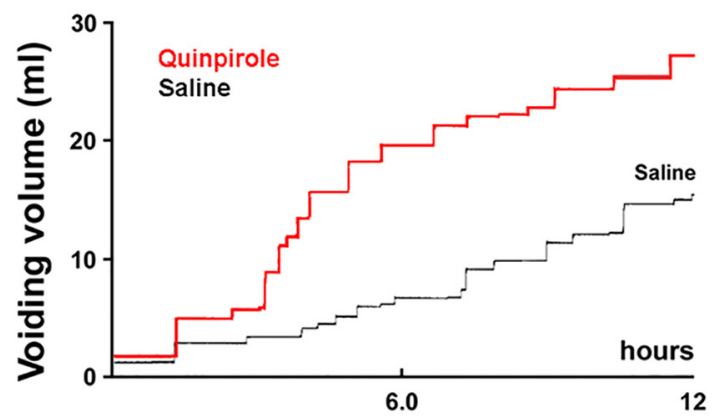

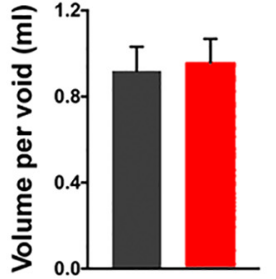
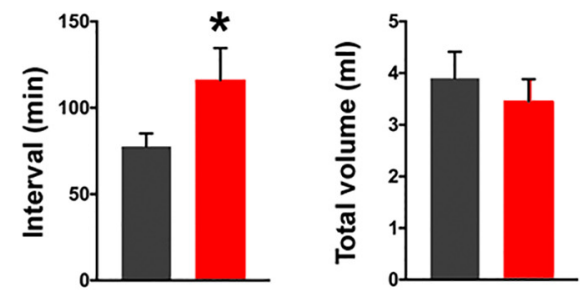

Saline
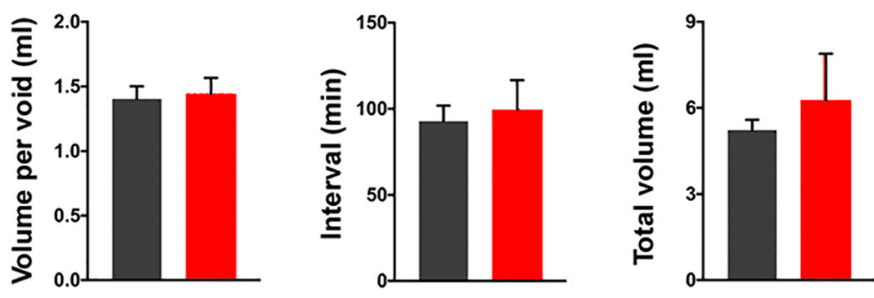

Saline

APO
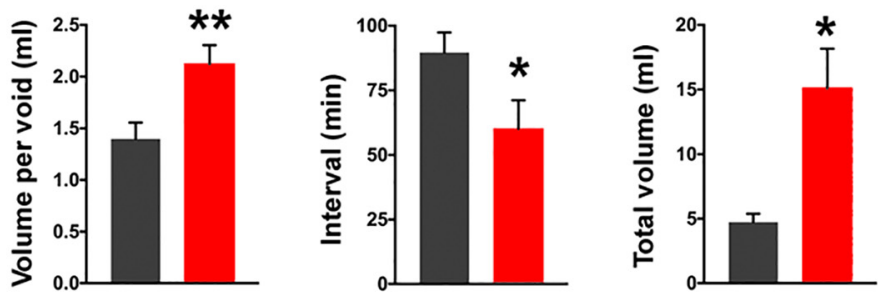

Saline

\section{Quinpirole}

Figure 10. Representative traces show volume-frequency patterns of spontaneous micturition in metabolic cage assays in SCI rats during 12-h recordings. In each "step-like" curve $(\boldsymbol{A}-\boldsymbol{C})$, the horizontal line represents the $\mathrm{VI}$, and the vertical line depicts the volume of urine expelled. $\boldsymbol{A}$, Statistical analysis demonstrates that within $6 \mathrm{~h}$ after subcutaneous delivery of L-DOPA, the VI is prolonged $\left({ }^{*} p<0.05\right.$, paired $t$ test) when compared with vehicle injections, but the volume of expelled urine does not change. $\boldsymbol{B}$, Injections of APO, a non-selective DR agonist, does not generate detectable changes in the spontaneous micturition reflex (all $p>0.05$ ). $\boldsymbol{C}$, Specific stimulation of spinal $\mathrm{DR}_{2}$ with quinpirole induces a dramatic increase in the amount of urine released per void $\left({ }^{* *} p<0.01\right)$ and the total volume of urine expelled $\left({ }^{*} p<0.05\right)$ as compared to vehicle delivery within the 6 -h period. Additionally, this drug decreases the interval between voids $\left({ }^{*} p<0.05\right)$ when compared to the control.

voiding activity, thereby facilitating urine elimination in SCl rats.

\section{Discussion}

The present study used DR agonists and antagonists to demonstrate that endogenous spinal DAergic mechanisms regulate the micturition reflex in $\mathrm{SCl}$ rats. It appears that DA modulation of LUT function is directed primarily at the EUS spinal pathway. Activation of both $\mathrm{DR}_{1}$ and $\mathrm{DR}_{2}$ facilitates voiding but these responses occur by different mechanisms that target different components of spinal EUS control: $\mathrm{DR}_{1}$ act on both tonic and bursting EUS activity while $\mathrm{DR}_{2}$ mainly act on EUS bursting. $\mathrm{DR}_{1}$ are tonically activated to inhibit tonic EUS activity and blocking this subtype enhances urine storage. $\mathrm{DR}_{2}$ have a minimal role during urine storage but stimulating this subtype increases EUS bursting during voiding (Fig. 11). The role of these two subtypes in the recovered micturition reflex of $\mathrm{SCl}$ rats is similar to that which was previously reported in spinal cord intact rats (Seki et al., 2001). Administration of the DA precursor L-DOPA or the non-selective DR agonist APO during CMG and EUS EMG recordings enhances voiding mechanisms. On the contrary, the selective $\mathrm{DR}_{1}$ antagonist SCH 23390 reduces voiding efficiency. These studies provide evidence that the DAergic neurons identified in the caudal spinal cord of SCI rats (Hou et al., 2016) are active and tonically modulate LUT function. If similar mechanisms are present in humans with $\mathrm{SCl}$, it is possible that pharmacological manipulation of the spinal DAergic system could be utilized to treat neurogenic LUT disorders. 


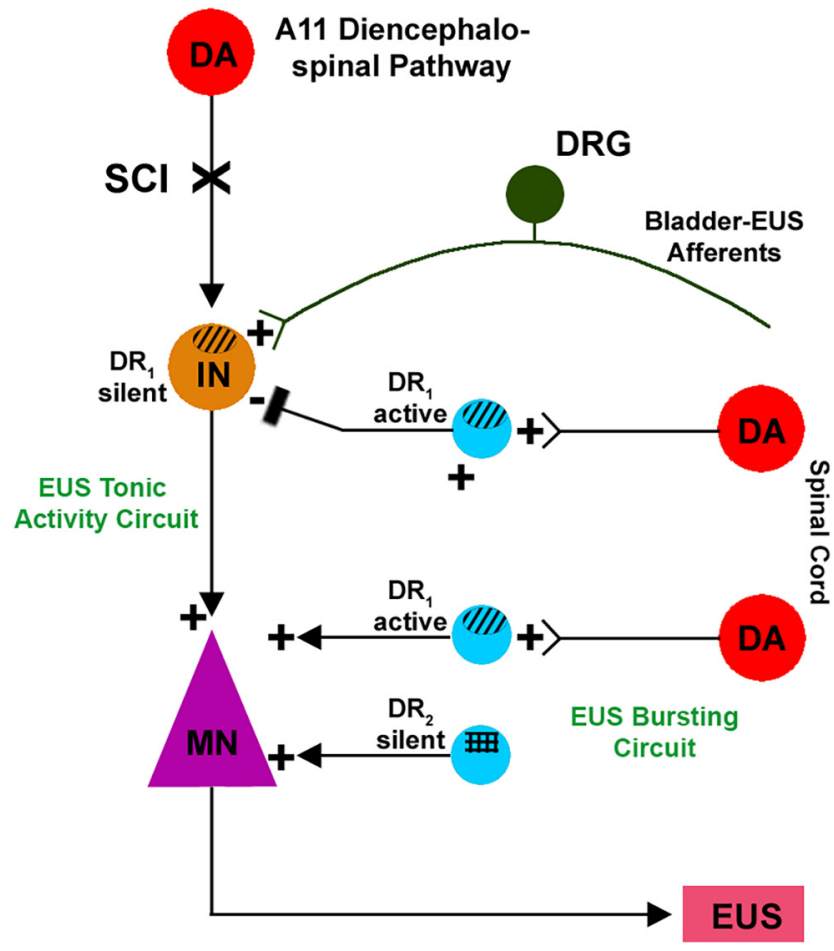

Figure 11. Schematic illustration showing putative DA regulation after $\mathrm{SCl}$ of the spinal disynaptic pathway mediating tonic EUS activity during urine storage and the EUS bursting activity during voiding. In the L6/S1 spinal cord, an excitatory interneuron (IN; brown) receives primary bladder-EUS afferent inputs and synapses with an EUS motoneuron (MN; violet) to form a spinal reflex pathway that generates tonic EUS activity. In spinal intact rats, this circuit is modulated by the A11 DAergic diencephalospinal pathway that activates $\mathrm{DR}_{1}$ on INs. After $\mathrm{SCl}$, the descending projection is interrupted and the modulation by $\mathrm{DR}_{1}$ is silenced, while the EUS tonic activity circuit is tonically modulated by a non-DA inhibitory IN (blue) activated by spinal DA neurons (red) via $D_{1}$. Blocking $\mathrm{DR}_{1}$ with $\mathrm{SCH} 23390$ eliminates the tonic inhibitory modulation and enhances EUS tonic activity. On the other hand, the EUS MN also generates bursting activity during voiding. One population of excitatory INs is tonically active in response to stimulation by endogenous $D A$ of $D R_{1}$. Accordingly, blocking $\mathrm{DR}_{1}$ in these neurons with $\mathrm{SCH} 23390$ suppresses bursting. Another population of local INs that express $\mathrm{DR}_{2}$ but are silent because they lack DAergic innervation, also facilitate EUS bursting when activated by quinpirole. Because these receptors are normally silent, selective blockage of these receptors with the $\mathrm{DR}_{2}$ antagonist remoxipride does not alter bursting activity whereas it can block the enhancement of bursting that occurs when quinpirole activates the receptors.

\section{SCl eliminates the excitatory effects of L-DOPA and APO on the bladder}

It is widely accepted that following $\mathrm{SCl}$, the spinal cord below the lesion undergoes adaptive changes at structural, cellular and molecular levels (Edgerton et al., 2004; Sadlaoud et al., 2010). The loss of supraspinal transport of neurotransmitters and degeneration of bulbospinal pathways triggers upregulation/downregulation of different receptors, second messengers, and ion channels (Ogawa et al., 2008; Boulenguez et al., 2010; Kong et al., 2010), which alters the activity of spinal neurons.
This neuroplasticity is implicated in both the process of urinary functional recovery and the development of neurogenic bladder symptoms, e.g., bladder hyperreflexia and DSD, at the chronic stage (Miyazato et al., 2013). Manual bladder expression helps expel residual urine. It also stimulates bladder sensory input and thus contributes to the establishment of segmental neuronal circuits that mediate spontaneous micturition recovery. The marked change in bladder activity in response to L-DOPA after SCl may reflect this plasticity. In spinal cord intact rats, systemic administration of L-DOPA combined with carbidopa elicited bladder hyperactivity that is mediated by activation of tachykinin mechanisms in the brain, leading to activation of descending noradrenergic pathways that activate $\alpha-1$ adrenoceptors in the spinal cord (Ishizuka et al., 1997, 2000). However, in $\mathrm{SCl}$ rats this effect of L-DOPA is replaced by a prominent effect on EUS function that enhances voiding efficiency and has a suppressant effect on the bladder which decreases the VA of bladder contractions. Because the high dose of L-DOPA reduced the events of NVCs, decreased VA of bladder contractions is likely caused by suppression of the parasympathetic efferent limb rather than a passive response to reduced outlet resistance. APO, a non-selective DR agonist which excites the bladder in spinal cord intact rats (Uchiyama et al., 2009), mimics the effect of L-DOPA after SCl, increasing voiding efficiency and reducing residual volume without changing bladder capacity during spontaneous voiding. Previous studies showed that APO causes detrusor overactivity and biphasic effects on voiding in spinal cord intact rats (Pehrson and Andersson, 2003; Uchiyama et al., 2009), but these changes were not observed in $\mathrm{SCl}$ rats. Quinpirole, a selective $\mathrm{DR}_{2}$ agonist, also increased the voiding efficiency. These data indicate that $\mathrm{SCl}$ eliminates the excitatory effects of L-DOPA and APO on the bladder and unmasks $\mathrm{DR}_{2}$-mediated effects on the EUS that promote voiding.

\section{The mechanisms of $\mathrm{DR}_{\mathbf{2}}$ in EUS bursting to improve voiding}

EUS bursting which consists of APs and SPs (Cheng and de Groat, 2004) is necessary for efficient voiding in rats (Peng et al., 2008; Langdale and Grill, 2016) and is reduced or masked after SCl (Yokoyama et al., 2000; Chang et al., 2007). The reduction in the ratio of SPs to APs during bursting in combination with a decrease in the bursting duration and an increase in tonic EUS activity cause DSD and inefficient voiding (Cheng and de Groat, 2004). Conversely, a longer EUS bursting duration indicates a more prolonged period of urethral relaxation and improved voiding while increased amplitude of intravesical pressure during voiding (VA) can reflect an increase in urethral outlet resistance or an increase in the parasympathetic excitatory input outflow to the bladder (Dolber et al., 2007). The mechanisms underlying $\mathrm{DR}_{2}$ mediated improvement in voiding were identified in combined $C M G$ and EUS EMG recordings where quinpirole increased the duration of bursting EUS activity during voiding and coordinated the detrusor and EUS activity, which resulted in 
dramatically improved voiding efficiency in single CMG experiments. After stimulating $\mathrm{DR}_{2}$ with quinpirole, the increase in the VI during continuous CMG could be explained by the decrease in the residual volume which then requires a longer filling time to reach the threshold volume for triggering a voiding reflex. Correspondingly, the changes in bladder activity may be indirect because of changes in EUS activity resulting in more efficient bladder emptying. This is supported by the lack of effects on bladder capacity in single CMG studies. Accordingly, it may indicate that activation of $\mathrm{DR}_{2}$ only targets EUS mechanisms to improve voiding and has no direct effect on the neural control of the bladder. In metabolic cage assays, stimulating $\mathrm{DR}_{2}$ with quinpirole markedly increased both the volume per void and total voiding volume. Previous studies reported that activation of $\mathrm{DR}_{2}$ in the kidney increases sodium excretion and urine flow (Felder et al., 1989; Siragy et al., 1990; Ozono et al., 2003). Therefore, an increase in the volume per void could be because of an increase in voiding efficiency while an increase in total urine volume that was released often indicates an elevation in the production of urine by the kidney, which can account for the decrease in the $\mathrm{VI}$ or increase in frequency of voids.

Bladder C-fiber afferents sprout after $\mathrm{SCl}$ and become hyperexcitable to trigger voiding dysfunction (Yoshimura et al., 2003; Cheng and de Groat, 2004). As quinpirole prolongs bursting, it is tempting to speculate that endogenous $\mathrm{DA}$ acting on $\mathrm{DR}_{2}$ regulates the spinal pathway activated by C-fiber afferents. In rats with thoracic spinal cord transection, EUS bursting is dependent on connections with a bursting center in the L3-L4 spinal cord (Chang et al., 2007, 2018; Karnup and de Groat, 2020a,b), thus activation of $\mathrm{DR}_{2}$ at this site may be responsible for the DAergic enhancement of bursting (Fig. 11). However, this $\mathrm{DR}_{2}$-mediated physiological regulation was not active under the experimental conditions because remoxipride, a $\mathrm{DR}_{2}$ antagonist, alone did not have any effect on reflex micturition parameters. It is therefore reasonable to conclude that spinal $\mathrm{DR}_{2}$ do not actively modulate recovered LUT function, or an alternative neurotransmitter system compensates for the contribution of these receptors. Based on previous reports (Pikov and Wrathall, 2002; de Groat and Yoshimura, 2006) and our preliminary data, the neurotransmitter glutamate can be released in the injured spinal cord and its receptors may mediate a decisive role in EUS activity.

In single CMG experiments, agents that supposedly stimulated $\mathrm{DR}_{2}$ (L-DOPA, APO and quinpirole) significantly increased voiding efficiency, decreased the residual volume and produced a non-significant increase in the voiding volume. However, there was not a consistent effect among these three agents on the amplitude of intravesical pressure during voiding in continuous CMG recordings, which would be expected to decline with reduced urethral outlet resistance and improved voiding. This variability might reflect different effects on the neural control of the bladder with some doses of these agents because of stimulation or inhibition of the parasympathetic pathway to the bladder (de Groat, 2006). Parasympathetic reflex control of the bladder in $\mathrm{SCl}$ rodents is complicated because contractile activity is initiated by two afferent pathways located at the T13/L1 and L6/S1 spinal levels. NVCs are triggered by capsaicin sensitive C-fiber afferents whereas bladder capacity and the initiation of voiding are triggered by $\mathrm{A}-\delta$ afferents (Cheng and de Groat, 2004; Takahashi et al., 2013; Kadekawa et al., 2017). L-DOPA and APO promoted the storage function of the bladder by reducing the number of NVCs but these agents did not change bladder capacity. Thus, they must have a selective effect on the afferent-interneuronal limb of the C-fiber triggered reflex pathway. Remoxipride in the same dose that blocked the effect of quinpirole, did not eliminate or reduce improved EUS bursting activity that was induced by L-DOPA or APO, which suggests that this effect is not mediated via $D_{2}$. Because stimulating $\mathrm{DR}_{1}$ with SKF 38393 alone did not influence EUS bursting nor voiding as described below, it is plausible that the effects of the DA precursor, L-DOPA, or the non-selective agonist APO on these parameters results from activation of spinal targets that express both $\mathrm{DR}_{1 /}$ 2. Alternatively, these two drugs may have another mechanism in addition to activation of $\mathrm{DR}_{1 / 2}$, such as a $D_{1}-D_{2}$ receptor heteromer which was reported to exist in the striatum (Hasbi et al., 2011, 2017). Certainly, this assumption needs additional experiments to be verified.

\section{The complexity of $\mathrm{DR}_{1}$ machinery in EUS tonic activity to maintain continence}

EUS tonic activity, which is important for the maintenance of continence during bladder filling and can also influence voiding after $\mathrm{SCl}$, was altered by drugs acting on DRs. At the onset of voiding, tonic EUS activity is suppressed and converted to bursting to increase voiding in spinal intact rats while the persistence of tonic activity during voiding after $\mathrm{SCl}$ contributes to the occurrence of DSD and reduces voiding efficiency. Because both L-DOPA and APO suppress tonic EUS activity that occurs before voiding and $\mathrm{SCH} 23390$, a $\mathrm{DR}_{1}$ antagonist, but not remoxipride, eliminates this effect, it is likely that the agonists act on $D_{1}$ to increase the firing of inhibitory interneurons that suppress tonic EUS activity and SCH 23390 blocks this action. However, SCH 23390 alone increases tonic EUS activity which makes it difficult to interpret its interactions with the agonists although one possible explanation for these observations is that tonic EUS activity is tonically suppressed by the putative inhibitory interneurons activated by endogenous $D A$ and $D R_{1}$. One additional complication is that SKF 38393, a $\mathrm{DR}_{1}$ agonist, also enhances tonic EUS activity. The seemingly paradoxical excitatory effects of both a $\mathrm{DR}_{1}$ agonist and antagonist raises the possibility that $D R_{1}$ receptors are located at two separate sites of spinal circuitry that generate opposing effects on EUS function (Fig. 11). That is to say, one population of receptors activated by spinal DA (Hou et al., 2016) after SCI mediates tonic inhibition of EUS activity and blocking these receptors enhances this activity. The other $\mathrm{DR}_{1}$ site, which stimulates EUS activity, may be activated by the diencephalospinal DAergic pathway in spinal intact rats which is interrupted by 
spinal transection. This $\mathrm{DR}_{1}$ site is not activated by spinal DA interneurons and is therefore inactive after $\mathrm{SCl}$ interrupts the descending pathway. Thus, blocking this site does not change EUS activity. However, pharmacologically activating this site with SKF 38393 stimulates EUS activity. This effect is consistent with the known excitatory effects of $\mathrm{DR}_{1}$ agonists on the central pattern generator in SCl rats (Seth et al., 1993) and the direct excitatory effect of $\mathrm{DR}_{1}$ agonists on spinal motoneurons (Han and Whelan, 2009).

In rats with $\mathrm{SCl}$, bladder overdistension increases excitability of bladder-related dorsal root ganglion (DRG) neurons, and injury itself elevates local nerve growth factor (NGF) levels within the cord and peripheral organs which stimulates C-fiber afferent sprouting (de Groat and Yoshimura, 2010), as described above. These factors contribute to bladder hyperreflexia during bladder filling as demonstrated by previous work in which desensitizing C-fiber afferents with capsaicin treatment suppresses bladder NVCs, partially normalizes EUS activity and improves voiding (Cheng and de Groat, 2004), indicating that these sensory afferents trigger voiding dysfunction. Recent studies showed that $\sim 8-10 \%$ of DRG neurons express TH (Brumovsky et al., 2012) and small diameter unmyelinated nociceptive neurons express $D_{1}$ and $D_{5}$ receptors (Li et al., 2005; Kline et al., 2009; Galbavy et al., 2013). This suggests that DA regulation of the micturition reflex may occur via targeting sensory afferents before acting on the efferent limb. This raises the possibility that the silent $D R_{1}$ mechanism which mediates EUS activity in response to SKF 38393 is located on the sensory limb of the EUS reflex pathway at the level of primary afferent terminals in the dorsal horn. Receptors in the dorsal horn and on EUS motoneurons may be activated by supraspinal input in spinal intact rats because both sites receive input from the A11 DAergic pathway (Holstege et al., 1996) and therefore would become silent in SCl rats after destruction of the descending DAergic pathway. The $\mathrm{DR}_{1}$ site that responds to L-DOPA or APO to produce inhibition and the other site that responds to SKF 38393 to produce excitation may exhibit this selectivity because of differences in DAergic innervation. L-DOPA could selectively target $\mathrm{DR}_{1}$ expressed by inhibitory neurons that are innervated by spinal DA interneurons (Fig. 11) while the $\mathrm{DR}_{1}$ site in the dorsal horn does not receive DAergic input after $\mathrm{SCl}$ and, therefore, does not respond to L-DOPA. On the other hand, $\mathrm{DR}_{1}$ in the dorsal horn are presumed to be denervated and thus, L-DOPA would be less effective but SKF 38393, the direct agonist, might be more effective.

The reason for the selectivity of the nonselective agonist, $\mathrm{APO}$, for $\mathrm{DR}_{1}$ in the inhibitory pathway is unclear. In the present study, we observed a reduced number of bladder NVCs when delivering L-DOPA or APO to stimulate DR. It is rational to assume that these drugs may reduce bladder hyperreflexia by first activating inhibitory $D_{1}$ expressed on $\mathrm{C}$-fiber bladder afferents which in turn, indirectly affect EUS motoneurons. Certainly, this machinery could directly affect motor neurons to suppress EUS tonic activity and temporarily provide inhibitory modulation of parasympathetic preganglionic neurons to maintain low amplitudes of bladder contractions as well. Thus, the action of L-DOPA to improve voiding efficiency in $\mathrm{SCl}$ rats is attributable to both an enhancement of EUS bursting and a suppression of EUS tonic activity which together reduce urethral outlet resistance and improve urine flow.

\section{Spinal DA neurons control bladder and EUS function}

A comparison of the effect of DA drugs on EUS and bladder activity in $\mathrm{SCl}$ rodents has revealed some interesting similarities. For example, the amplitude of bladder contractions and tonic EUS activity are both enhanced by the $\mathrm{DR}_{1}$ antagonist $\mathrm{SCH} 23390$, suggesting that both organs are subject to tonic inhibition involving $D_{1}$ or as mentioned above that the increase in tonic EUS activity induced by the drug indirectly increases bladder contractions because of increased residual volume. Meanwhile, the $\mathrm{DR}_{2}$ antagonist, remoxipride, does not affect EUS or bladder activity indicating that neither organ is subject to tonic modulation by $\mathrm{DR}_{2}$. However, the $\mathrm{DR}_{2}$ agonist, quinpirole, enhances EUS bursting and bladder contractions suggesting that $\mathrm{DR}_{2}$ are normally silent after $\mathrm{SCl}$ but can be activated by direct stimulation. These observations raise the possibility that some bladder and EUS functions may be controlled by the same populations of spinal DA neurons and that $\mathrm{DR}_{2}$ are innervated by input from $\mathrm{DA}$ neurons in the brain and become silent after elimination of this input following SCl. Regarding the highly sexually dimorphic LUT system, selected DR agonists and antagonists were employed in male rats with $\mathrm{SCl}$ for urodynamic assays and similar responses were observed in males (Qiao et al., 2021). Therefore, there is no obvious sex difference in spinal DA regulation of micturition function in rats.

\section{Considerations of drug delivery routes and others}

Although dramatic effects were detected by delivering L-DOPA or APO during continuous bladder CMG and EUS EMG recordings, these two drugs rarely affected spontaneous micturition in metabolic cages as expected. Given that they were administered intravenously in the former but subcutaneously in the latter, this discrepancy is possibly because of different delivery routes. Drugs with intravenous dosing can immediately reach the spinal cord to elicit a rapid onset effect while their diffusion is much slower via subcutaneous injection that produces a more gradual effect in metabolic cage assays. It was reported that APO, when given orally, removes around 40$60 \%$ of the contents in the stomach (Borkar et al., 2017) and is ineffective in inducing central responses because of the first-pass effect (Subramony, 2006). Here, one subcutaneous bolus injection of APO might have similar metabolic constraints. Because of the high levels of decarboxylase present within the liver which is the first passage to the CNS, subcutaneous injections of L-DOPA appear to share a common low bioavailability even when co-delivered with a low dose of the metabolic inhibitor, carbidopa (Schneider et al., 2018). Although all drugs in our experiments were administered in the periphery, we 
assume that the effects on LUT function were mediated by actions on the spinal cord because there are very few reports of DR expression within the urinary tract (de Groat, 2006; Winge and Fowler, 2006; Arrighi et al., 2009). Furthermore, we observed consistent urodynamic responses with intravenous and intrathecal drug administration in a pilot experiment. This indicates that DA has no or very subtle peripheral influences on the LUT system.

Although this research did not study the possible alteration of DRs responsible for $\mathrm{SCl}$, plasticity of DRs is certainly an important topic in micturition control, which could have a potential impact on clinical applications. Initially, we found that EUS bursting activity, an important parameter to evaluate voiding, was easily masked in SCl rats if urethane was used. Therefore, we conducted the experiments in $\mathrm{SCl}$ rats under awake conditions. However, urethane-anesthetized naive rats were used to reduce pain for comparison of bladder CMG and EUS EMG reflex patterns. It is thus a limitation that naive rats were sedated but $\mathrm{SCl}$ rats were not. Nevertheless, differences between these two states can be obtained from previous publications (Cheng and de Groat, 2004; Kadekawa et al., 2016).

In conclusion, under normal conditions, well-coordinated detrusor-sphincter activity generates successful storage and emptying. After SCl in rats, the reestablished spinal micturition reflex circuit mediates involuntary voiding but the bladder becomes hyperactive and DSD occurs. This results in inefficient voiding, urinary retention or leakage (Cheng and de Groat, 2004). It is unclear whether the reestablished pathway is a newly-formed neuronal circuit or forms due to the reemergence of existing circuits that normally become silent throughout development. However, it is known that SCl triggers the reorganization of synaptic connections in spinal circuitry that regulates the LUT (de Groat, 2002; de Groat and Yoshimura, 2012). In the lumbosacral spinal cord, $\mathrm{TH}^{+}$neurons undergo plasticity and are an active component of micturition circuitry following $\mathrm{SCl}$, compensating for the loss of DA supply that is traditionally believed to emerge from supraspinal sources. Despite their capacity for DA synthesis, the low level of spinally-derived DA may be insufficient to fully modulate urinary function. Accordingly, spinal DR may be used for therapeutic intervention. In this study, pharmacological manipulation of spinal DAergic pathways can suppress bladder hyperreflexia and remarkably increase detrusor-sphincter coordination in $\mathrm{SCl}$ rats, leading to significantly improved voiding efficiency. It is possible that DA signaling modulates other intraspinal neurotransmitters to achieve these effects (Ogawa et al., 2006; Han et al., 2007). Although multiple neurotransmitter systems are involved in micturition, manipulating DAergic mechanisms alone is sufficient to achieve meaningful micturition improvement in $\mathrm{SCl}$ rats. Additionally, a clinical study reported that APO increased bladder contractions while decreasing urethral opening pressure to facilitate voiding in SCl patients (Steers et al., 2000), suggesting that DAergic mechanisms also exist in the human spinal cord and regulate LUT activity. Hence, pharmacological stimulation of spinal DAergic pathways may become a therapeutic strategy for promoting LUT functional recovery after $\mathrm{SCl}$.

\section{References}

Araki I, de Groat WC (1997) Developmental synaptic depression underlying reorganization of visceral reflex pathways in the spinal cord. J Neurosci 17:8402-8407.

Aranda B, Cramer P (1993) Effects of apomorphine and L-dopa on the parkinsonian bladder. Neurourol Urodyn 12:203-209.

Arrighi N, Bodei S, Zani D, Simeone C, Fiorentini C, Missale C, Milanese G, Dellabella M, Muzzonigro G, Cunico SC, Spano P, Sigala S (2009) Molecular and pharmacological detection of dopaminergic receptors in the human male urinary tract. Neurourol Urodyn 28:343-348.

Ballester González J, Dvorkin-Gheva A, Silva C, Foster JA, Szechtman H (2015) Nucleus accumbens core and pathogenesis of compulsive checking. Behav Pharmacol 26:200-216.

Borkar N, Andersson DR, Yang M, Müllertz A, Holm R, Mu H (2017) Efficacy of oral lipid-based formulations of apomorphine and its diester in a Parkinson's disease rat model. J Pharm Pharmacol 69:1110-1115.

Boulenguez $\mathrm{P}$, Liabeuf $\mathrm{S}$, Bos R, Bras $\mathrm{H}$, Jean-Xavier C, Brocard C, Stil A, Darbon P, Cattaert D, Delpire E, Marsala M, Vinay L (2010) Down-regulation of the potassium-chloride cotransporter KCC2 contributes to spasticity after spinal cord injury. Nat Med 16:302307.

Brooks DJ (2008) Optimizing levodopa therapy for Parkinson's disease with levodopa/carbidopa/entacapone: implications from a clinical and patient perspective. Neuropsychiatr Dis Treat 4:39-47.

Brumovsky PR, La JH, McCarthy CJ, Hökfelt T, Gebhart GF (2012) Dorsal root ganglion neurons innervating pelvic organs in the mouse express tyrosine hydroxylase. Neuroscience 223:77-91.

Calabrese V, Mancuso C, Ravagna A, Perluigi M, Cini C, De Marco C, Butterfield DA, Stella AM (2007) In vivo induction of heat shock proteins in the substantia nigra following L-DOPA administration is associated with increased activity of mitochondrial complex I and nitrosative stress in rats: regulation by glutathione redox state. $\mathrm{J}$ Neurochem 101:709-717.

Celesia GG, Wanamaker WM (1976) L-dopa-carbidopa: combined therapy for the treatment of Parkinson's disease. Dis Nerv Syst 37:123-125.

Chang HH, Yeh JC, Ichiyama RM, Rodriguez LV, Havton LA (2018) Mapping and neuromodulation of lower urinary tract function using spinal cord stimulation in female rats. Exp Neurol 305:26-32.

Chang HY, Cheng CL, Chen JJ, de Groat WC (2007) Serotonergic drugs and spinal cord transections indicate that different spinal circuits are involved in external urethral sphincter activity in rats. Am J Physiol Renal Physiol 292:F1044-F1053.

Cheng CL, de Groat WC (2004) The role of capsaicin-sensitive afferent fibers in the lower urinary tract dysfunction induced by chronic spinal cord injury in rats. Exp Neurol 187:445-454.

Contin M, Martinelli P (2010) Pharmacokinetics of levodopa. J Neurol 257:S253-S261.

de Groat WC (1995) Mechanisms underlying the recovery of lower urinary tract function following spinal cord injury. Paraplegia 33:493-505.

de Groat WC (2002) Plasticity of bladder reflex pathways during postnatal development. Physiol Behav 77:689-692.

de Groat WC (2006) Integrative control of the lower urinary tract: preclinical perspective. Br J Pharmacol 147 [Suppl 2]:S25-S40.

de Groat WC, Yoshimura N (2006) Mechanisms underlying the recovery of lower urinary tract function following spinal cord injury. Prog Brain Res 152:59-84.

de Groat WC, Yoshimura N (2010) Changes in afferent activity after spinal cord injury. Neurourol Urodyn 29:63-76.

de Groat WC, Yoshimura N (2012) Plasticity in reflex pathways to the lower urinary tract following spinal cord injury. Exp Neurol 235:123-132. 
de Groat WC, Araki I, Vizzard MA, Yoshiyama M, Yoshimura N, Sugaya K, Tai C, Roppolo JR (1998) Developmental and injury induced plasticity in the micturition reflex pathway. Behav Brain Res 92:127-140.

Dolber PC, Gu B, Zhang X, Fraser MO, Thor KB, Reiter JP (2007) Activation of the external urethral sphincter central pattern generator by a 5-HT(1A) receptor agonist in rats with chronic spinal cord injury. Am J Physiol Regul Integr Comp Physiol 292:R1699R1706.

Edgerton VR, Tillakaratne NJ, Bigbee AJ, de Leon RD, Roy RR (2004) Plasticity of the spinal neural circuitry after injury. Annu Rev Neurosci 27:145-167.

Falla D, Jull G, Dall'Alba P, Rainoldi A, Merletti R (2003) An electromyographic analysis of the deep cervical flexor muscles in performance of craniocervical flexion. Phys Ther 83:899-906.

Felder RA, Felder CC, Eisner GM, Jose PA (1989) The dopamine receptor in adult and maturing kidney. Am J Physiol 257:F315-F327.

Fowler CJ, Griffiths D, de Groat WC (2008) The neural control of micturition. Nat Rev Neurosci 9:453-466.

Galbavy W, Safaie E, Rebecchi MJ, Puopolo M (2013) Inhibition of tetrodotoxin-resistant sodium current in dorsal root ganglia neurons mediated by D1/D5 dopamine receptors. Mol Pain 9:60.

Gancher S (1995) Pharmacokinetics of apomorphine in Parkinson's disease. J Neural Transm Suppl 45:137-141.

Giorgi O, Pibiri MG, Loi R, Corda MG (1993) Chronic treatment with SCH 23390 increases the production rate of dopamine D1 receptors in the nigro-striatal system of the rat. Eur $\mathrm{J}$ Pharmacol 245:139-145.

Han P, Whelan PJ (2009) Modulation of AMPA currents by D(1)-like but not $D(2)$-like receptors in spinal motoneurons. Neuroscience 158:1699-1707.

Han P, Nakanishi ST, Tran MA, Whelan PJ (2007) Dopaminergic modulation of spinal neuronal excitability. J Neurosci 27:1319213204.

Hasbi A, O'Dowd BF, George SR (2011) Dopamine D1-D2 receptor heteromer signaling pathway in the brain: emerging physiological relevance. Mol Brain 4:26.

Hasbi A, Perreault ML, Shen MYF, Fan T, Nguyen T, Alijaniaram M, Banasikowski TJ, Grace AA, O'Dowd BF, Fletcher PJ, George SR (2017) Activation of dopamine D1-D2 receptor complex attenuates cocaine reward and reinstatement of cocaine-seeking through inhibition of DARPP-32, ERK, and deltaFosB. Front Pharmacol 8:924.

Hietala J, Seppäla T, Lappalainen J, Syvälahti E (1992) Quantification of SCH 39166, a novel selective D1 dopamine receptor antagonist, in rat brain and blood. Psychopharmacology (Berl) 106:455-458.

Holstege JC, Van Dijken H, Buijs RM, Goedknegt H, Gosens T, Bongers CM (1996) Distribution of dopamine immunoreactivity in the rat, cat and monkey spinal cord. J Comp Neurol 376:631-652.

Hou S, Carson DM, Wu D, Klaw MC, Houlé JD, Tom VJ (2016) Dopamine is produced in the rat spinal cord and regulates micturition reflex after spinal cord injury. Exp Neurol 285:136-146.

Ishizuka O, Pandita RK, Mattiasson A, Steers WD, Andersson KE (1997) Stimulation of bladder activity by volume, L-dopa and capsaicin in normal conscious rats-effects of spinal alpha 1-adrenoceptor blockade. Naunyn Schmiedebergs Arch Pharmacol 355:787-793.

Ishizuka O, Igawa Y, Nishizawa O, Andersson KE (2000) Role of supraspinal tachykinins for volume- and L-dopa-induced bladder activity in normal conscious rats. Neurourol Urodynam 19:101109.

Ishizuka O, Gu BJ, Nishizawa O, Mizusawa H, Andersson KE (2002) Effect of apomorphine on intracavernous pressure and blood pressure in conscious, spinalized rats. Int J Impot Res 14:128-132.

Jiang HH, Salcedo LB, Song B, Damaser MS (2010) Pelvic floor muscles and the external urethral sphincter have different responses to applied bladder pressure during continence. Urology 75:1515.e1-7.

Kadekawa K, Yoshimura N, Majima T, Wada N, Shimizu T, Birder LA, Kanai AJ, de Groat WC, Sugaya K, Yoshiyama M (2016) Characterization of bladder and external urethral activity in mice with or without spinal cord injury-a comparison study with rats. Am J Physiol Regul Integr Comp Physiol 310:R752-R758.

Kadekawa K, Majima T, Shimizu T, Wada N, de Groat WC, Kanai AJ, Goto M, Yoshiyama M, Sugaya K, Yoshimura N (2017) The role of capsaicin-sensitive C-fiber afferent pathways in the control of micturition in spinal-intact and spinal cord-injured mice. Am J Physiol Renal Physiol 313:F796-F804.

Karnup SV, de Groat WC (2020a) Propriospinal neurons of L3-L4 segments involved in control of the rat external urethral sphincter. Neuroscience 425:12-28.

Karnup SV, de Groat WC (2020b) Mapping of spinal interneurons involved in regulation of the lower urinary tract in juvenile male rats. IBRO Rep 9:115-131.

King DJ, Devaney N, Cooper SJ, Blomqvist M, Mitchell MJ (1990) Pharmacokinetics and antipsychotic effect of remoxipride in chronic schizophrenic patients. J Psychopharmacol 4:83-89.

Kline DD, Hendricks G, Hermann G, Rogers RC, Kunze DL (2009) Dopamine inhibits $\mathrm{N}$-type channels in visceral afferents to reduce synaptic transmitter release under normoxic and chronic intermittent hypoxic conditions. J Neurophysiol 101:2270-2278.

Koblinger K, Jean-Xavier C, Sharma S, Füzesi T, Young L, Eaton SEA, Kwok CHT, Bains JS, Whelan PJ (2018) Optogenetic activation of a11 region increases motor activity. Front Neural Circuits 12:86.

Kong XY, Wienecke J, Hultborn H, Zhang M (2010) Robust upregulation of serotonin $2 \mathrm{~A}$ receptors after chronic spinal transection of rats: an immunohistochemical study. Brain Res 1320:60-68.

Langdale CL, Grill WM (2016) Phasic activation of the external urethral sphincter increases voiding efficiency in the rat and the cat. Exp Neurol 285:173-181.

Lee YS, Lin CY, Jiang HH, Depaul M, Lin VW, Silver J (2013) Nerve regeneration restores supraspinal control of bladder function after complete spinal cord injury. J Neurosci 33:10591-10606.

Li GH, Guan BC, Li ZW (2005) Effects of dopamine, SKF-38393 and $\mathrm{R}(-)-N P A$ on ATP-activated currents in rat DRG neurons. Can J Physiol Pharmacol 83:267-277.

Maggi CA, Santicioli P, Meli A (1986) Postnatal development of micturition reflex in rats. Am J Physiol 250:R926-R931.

Mitsui T, Fischer I, Shumsky JS, Murray M (2005a) Transplants of fibroblasts expressing BDNF and NT-3 promote recovery of bladder and hindlimb function following spinal contusion injury in rats. Exp Neurol 194:410-431.

Mitsui T, Shumsky JS, Lepore AC, Murray M, Fischer I (2005b) Transplantation of neuronal and glial restricted precursors into contused spinal cord improves bladder and motor functions, decreases thermal hypersensitivity, and modifies intraspinal circuitry. J Neurosci 25:9624-9636.

Miyazato M, Oshiro T, Chancellor MB, de Groat WC, Yoshimura N, Saito S (2013) An alpha1-adrenoceptor blocker terazosin improves urine storage function in the spinal cord in spinal cord injured rats. Life Sci 92:125-130.

Movin-Osswald G, Hammarlund-Udenaes M (1991) Remoxipride: pharmacokinetics and effect on plasma prolactin. $\mathrm{Br} \mathrm{J}$ Clin Pharmacol 32:355-360.

Ogawa T, Seki S, Masuda H, Igawa Y, Nishizawa O, Kuno S, Chancellor MB, de Groat WC, Yoshimura N (2006) Dopaminergic mechanisms controlling urethral function in rats. Neurourol Urodyn 25:480-489.

Ogawa T, Sasatomi K, Hiragata S, Seki S, Nishizawa O, Chermansky CJ, Pflug BR, Nelson JB, Chancellor MB, Yoshimura N (2008) Therapeutic effects of endothelin-A receptor antagonist on bladder overactivity in rats with chronic spinal cord injury. Urology 71:341-345.

Ozawa H, Yamaguchi T, Hamaguchi S, Yamaguchi S, Ueda S (2017) Three types of a11 neurons project to the rat spinal cord. Neurochem Res 42:2142-2153.

Ozono R, Ueda A, Oishi Y, Yano A, Kambe M, Katsuki M, Oshima T (2003) Dopamine D2 receptor modulates sodium handling via local production of dopamine in the kidney. J Cardiovasc Pharmacol 42 [Suppl 1]:S75-S79. 
Pahwa R, Koller WC (1996) Treatment of Parkinson's disease with controlled-release carbidopa/L-DOPA. Adv Neurol 69:487-491.

Park KH, Park HJ, Shin KS, Lee MK (2014) Multiple treatments with L-3,4-dihydroxyphenylalanine modulate dopamine biosynthesis and neurotoxicity through the protein kinase A-transient extracellular signal-regulated kinase and exchange protein activation by cyclic AMP-sustained extracellular signal-regulated kinase signaling pathways. J Neurosci Res 92:1746-1756.

Pehrson R, Andersson KE (2003) Tramadol inhibits rat detrusor overactivity caused by dopamine receptor stimulation. J Urol 170:272275.

Peng CW, Chen JJ, Chang HY, de Groat WC, Cheng CL (2006) External urethral sphincter activity in a rat model of pudendal nerve injury. Neurourol Urodyn 25:388-396.

Peng CW, Chen JJ, Cheng CL, Grill WM (2008) Role of pudendal afferents in voiding efficiency in the rat. Am J Physiol Regul Integr Comp Physiol 294:R660-R672.

Pértile RAN, Corvino ME, Marchette RCN, Pavesi E, Cavalli J, Ramos A, Izidio GS (2017) The quinpirole hypolocomotive effects are strain and route of administration dependent in SHR and SLA16 isogenic rats. Behav Genet 47:552-563.

Pikov V, Wrathall JR (2002) Altered glutamate receptor function during recovery of bladder detrusor-external urethral sphincter coordination in a rat model of spinal cord injury. J Pharmacol Exp Ther 300:421-427.

Qiao Y, Brodnik ZD, Zhao S, Trueblood CT, Li Z, Tom VJ, España RA, Hou S (2021) Spinal dopaminergic mechanisms regulating the micturition reflex in male rats with complete spinal cord injury. $J$ Neurotrauma 38:803-817.

Sadlaoud K, Tazerart S, Brocard C, Jean-Xavier C, Portalier P, Brocard F, Vinay L, Bras H (2010) Differential plasticity of the GABAergic and glycinergic synaptic transmission to rat lumbar motoneurons after spinal cord injury. J Neurosci 30:3358-3369.

Schneider F, Erisson L, Beygi H, Bradbury M, Cohen-Barak O, Grachev ID, Guzy S, Loupe PS, Levi M, McDonald M, Savola JM, Papapetropoulos S, Tracewell WG, Velinova M, Spiegelstein O (2018) Pharmacokinetics, metabolism and safety of deuterated LDOPA (SD-1077)/carbidopa compared to L-DOPA/carbidopa following single oral dose administration in healthy subjects. Br J Clin Pharmacol 84:2422-2432.

Seki S, Igawa Y, Kaidoh K, Ishizuka O, Nishizawa O, Andersson KE (2001) Role of dopamine D1 and D2 receptors in the micturition reflex in conscious rats. Neurourol Urodyn 20:105-113.

Seth P, Gajendiran M, Maitra KK, Ross HG, Ganguly DK (1993) Evidence for D1 dopamine receptor-mediated modulation of the synaptic transmission from motor axon collaterals to Renshaw cells in the rat spinal cord. Neurosci Lett 158:217-220.

Setler PE, Sarau HM, Zirkle CL, Saunders HL (1978) The central effects of a novel dopamine agonist. Eur J Pharmacol 50:419-430.

Siragy HM, Felder RA, Howell NL, Chevalier RL, Peach MJ, Carey RM (1990) Evidence that dopamine-2 mechanisms control renal function. Am J Physiol 259:F793-F800.
Skagerberg G, Lindvall O (1985) Organization of diencephalic dopamine neurones projecting to the spinal cord in the rat. Brain Res 342:340-351.

Soares-da-Silva P, Vieira-Coelho MA, Serrão MP (1997) Uptake of L3,4-dihydroxyphenylalanine and dopamine formation in cultured renal epithelial cells. Biochem Pharmacol 54:1037-1046.

Steers WD, Gray ML, Ames CD (2000) Effect of sublingual apomorphine on bladder function in patients with spinal cord injury. J Urol 163:39.

Stocchi F, Vacca L, Grassini P, Pawsey S, Whale H, Marconi S, Torti M (2015) L-Dopa pharmacokinetic profile with effervescent melevodopa/carbidopa versus standard-release levodopa/carbidopa tablets in Parkinson's disease: a randomised study. Parkinsons Dis 2015:369465.

Subramony JA (2006) Apomorphine in dopaminergic therapy. Mol Pharm 3:380-385.

Takahashi R, Yoshizawa T, Yunoki T, Tyagi P, Naito S, de Groat WC, Yoshimura N (2013) Hyperexcitability of bladder afferent neurons associated with reduction of Kv1.4 $\alpha$-subunit in rats with spinal cord injury. J Urol 190:2296-2304. S

Uchiyama T, Sakakibara R, Yoshiyama M, Yamamoto T, Ito T, Liu Z, Yamaguchi C, Awa Y, Yano HM, Yanagisawa M, Yamanishi T, Hattori T, Kuwabara S (2009) Biphasic effect of apomorphine, an anti-parkinsonian drug, on bladder function in rats. Neuroscience 162:1333-1338.

van Dijken H, Dijk J, Voom P, Holstege JC (1996) Localization of dopamine D2 receptor in rat spinal cord identified with immunocytochemistry and in situ hybridization. Eur J Neurosci 8:621-628.

Wachtel SR, Abercrombie ED (1994) L-3,4-dihydroxyphenylalanineinduced dopamine release in the striatum of intact and 6-hydroxydopamine-treated rats: differential effects of monoamine oxidase A and B inhibitors. J Neurochem 63:108-117.

Winge K, Fowler CJ (2006) Bladder dysfunction in Parkinsonism: mechanisms, prevalence, symptoms, and management. Mov Disord 21:737-745.

Yokoyama O, Yoshiyama M, Namiki M, de Groat WC (2000) Role of the forebrain in bladder overactivity following cerebral infarction in the rat. Exp Neurol 163:469-476.

Yoshimura N, Mizuta E, Yoshida O, Kuno S (1998) Therapeutic effects of dopamine D1/D2 receptor agonists on detrusor hyperreflexia in 1-methyl-4-phenyl-1,2,3,6-tetrahydropyridine-lesioned parkinsonian cynomolgus monkeys. J Pharmacol Exp Ther 286:228-233.

Yoshimura N, Kuno S, Chancellor MB, De Groat WC, Seki S (2003) Dopaminergic mechanisms underlying bladder hyperactivity in rats with a unilateral 6-hydroxydopamine (6-OHDA) lesion of the nigrostriatal pathway. Br J Pharmacol 139:1425-1432.

Zinck ND, Downie JW (2006) Plasticity in the injured spinal cord: can we use it to advantage to reestablish effective bladder voiding and continence? Prog Brain Res 152:147-162. 